\title{
Mimicry in the ultraviolet: A predator perspective
}

by

\author{
Casey Anne Peet-Paré
}

A thesis submitted to the Faculty of Graduate and Postdoctoral Affairs in partial fulfillment of the requirements for the degree of

Master of Science

in

\section{Biology}

Carleton University

Ottawa, Ontario

C 2016, Casey Anne Peet-Paré 


\begin{abstract}
The ubiquity of ultraviolet (UV) vision in animals means UV colour is as important to consider as visible colours when studying animal colouration. I first undertook a survey of recent animal behaviour research and determined that many studies still fail to account for UV vision and colour. Next I measured the visible and UV colour of hoverflies (Diptera: Syrphidae) months and decades since pinning to determine whether colour changed over time. I found no significant change in colour, supporting the use of preserved insects in colour research. Lastly, I tested whether hoverfly mimics resemble their hymenopteran models in the UV by scoring the strength of their UV reflection in photographs and obtaining spectral curves of hoverfly colours. I determined that there is a significant relationship between mimic and model thorax and abdomen UV colour and that mimics are significantly more similar to their potential hymenopteran models than to non-models in the UV.
\end{abstract}




\section{Acknowledgements}

First, I would like to thank my supervisor Tom Sherratt for his guidance, insight and support. I always leave our meetings feeling energized and optimistic.

Secondly, I would like to thank a number of other scientists, without whose help this project could not have happened: David Pfennig for loaning me his photography equipment (and David Kikuchi for making it happen); Jolyon Troscianko for his advice and input on my equipment and methods; Nate Morehouse for providing insight on UV vision and colour, and for donating his time and expertise in measuring the colour spectra of my specimens (greatly adding to the validity of my research); Jeff Skevington for his assistance collecting hoverflies and identifying them, and for all other things hoverfly related; Sophie Cardinal for her assistance with the hymenopteran specimens; Owen Lonsdale and the rest of the researchers at the $\mathrm{CNC}$ for allowing me access to the collection and providing me with a workspace (with special notice to Andrew Young and Trevor Burt); Changku Kang for his colour and vision expertise; and Richard Webster for his photography expertise.

I would also like to thank the rest of my committee - Jayne Yack and Jessica Forrest for their feedback and assistance, and of course thank my hardworking volunteers: Tammy Duong, Sophie Potter, Ryan Pusiak, and Chelsey Blackman for spending many, many hours looking through hundreds of UV photographs. 
Lastly, I couldn't have done it without the support of my parents, David and Susan, and my partner Adrien Gervais (who I now owe about two years' worth of dinners, dishes, and dog walks). 


\section{Table of Contents}

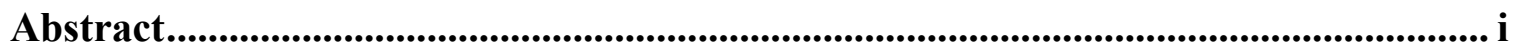

Acknowledgements ........................................................................................................................... ii

Table of Contents ........................................................................................................ iv

List of Tables ............................................................................................................................. vi

List of Figures.............................................................................................................................. viii

List of Appendices......................................................................................................................... xi

Introduction ...................................................................................................................................... xii

Chapter 1: Ultraviolet vision and colour .............................................................................. 1

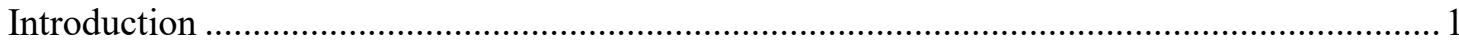

The ubiquity of ultraviolet colour and vision .....................................................................

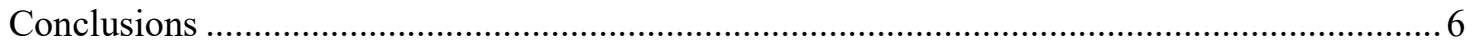

Chapter 2: Measuring insect colour ...................................................................................... 8

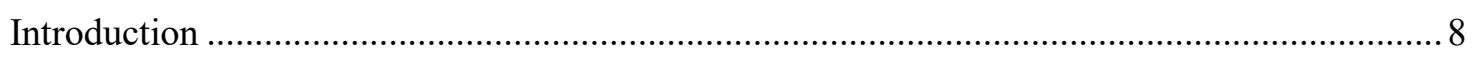

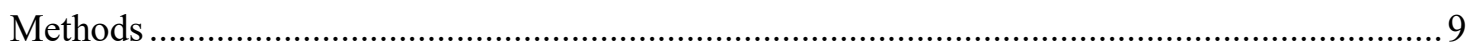

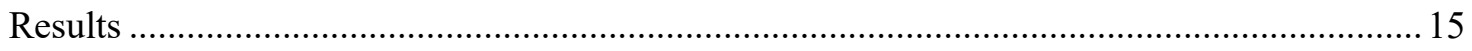

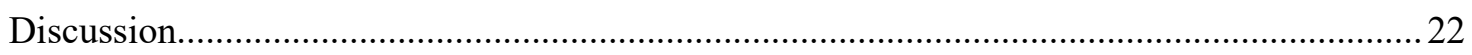

Chapter 3: Ultraviolet mimicry in hoverflies .................................................................... 26

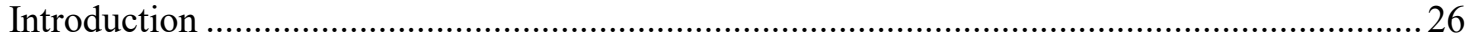

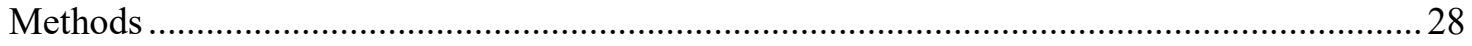

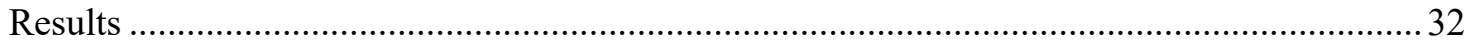

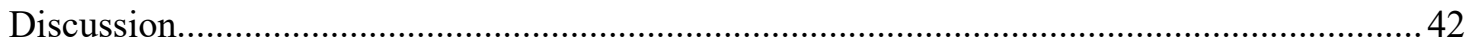

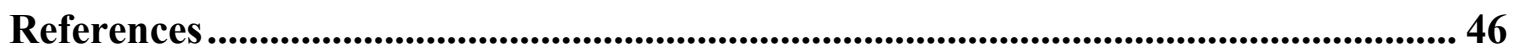




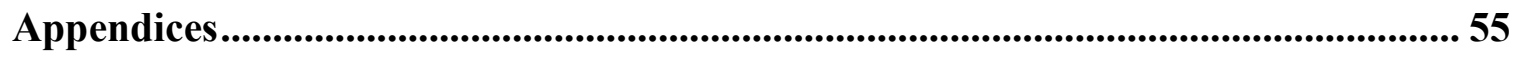

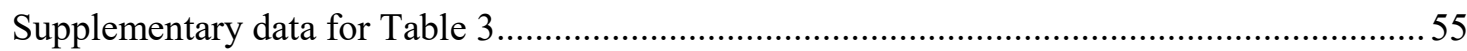




\section{List of Tables}

Table 1. Hypotheses for the persistence of imperfect mimicry (adapted from Kikuchi and

Pfennig, 2013) xvi

Table 2. A selection of potential hoverfly predators that possess UV sensitive vision. xvii

Table 3. A summary of the methods of 63 articles published in three top animal behaviour journals in the year 2015. The articles chosen focused on animals with ultraviolet (UV) vision, and made assumptions about how colours are perceived by receivers. UV - UV vision and colour was accounted for; No UV - UV colour and vision was not accounted for; Measured - the study measured or assessed animal colour; Models - the study used artificial models, video, or altered live animal colouration; Lighting - the study used artificial lighting. Note: a study may appear in the table more than once, although a study cannot be both "UV" and "No UV". A full list of the papers can be found in Supplementary Data

Table 4. Examples of human visible colours (400-700nm) which also reflect light in the UV spectrum (300-400nm) in a variety of animal species, and their proposed roles. 4

Table 5. The species or genus ID, number of specimens, and presence/absence of UV colour for the 92 hoverflies collected. The CNC collection numbers for all specimens can be found in the Specimen data excel file 
Table 6. Examples of UV reflective colours in a number of insect orders.

Table 7. Hoverfly mimics and their proposed hymenopteran models. Blue - bee species; Red - wasp species; Bolded - UV reflecting colour present in at least one body section. Mimic and model pairings were compiled from: Howarth et al., 2000; Howarth and

Edmunds, 2000; Edmunds and Reader, 2014 .......................................................... 33 


\section{List of Figures}

Figure 1. Normalized photoreceptor spectral sensitivities of: (A) human; (B) honeybee; (C) pigeon; (D) starling. X-axis is wavelength of light, $\mathrm{y}$-axis is percent absorption. Taken from Osorio and Vorobyev, 2008 xiii

Figure 2. The photography set up. The camera is on the right side of the diagram and is pointing at the specimen (tripod not shown) while the light is on the top left. 10

Figure 3. Visible and ultraviolet photographs of Eurimyia lineatus (A) and Syritta

pipiens (B)

Figure 4. Average pixel value of red (A), green (B), and blue (C) versus time (log(hours +1)) for the yellow abdominal markings of Syritta pipiens. Pixel values were measured from visible photos and 19 specimens were included. Results are significant (red: analysis of deviance, $\chi^{2}{ }_{1}=15.464, p<0.001$, green: $\chi^{2}{ }_{1}=9.544, p<0.01$, and blue: $\chi^{2}{ }_{1}$ $=4.965, \mathrm{p}<0.01)$ 17

Figure 5. Average pixel brightness value versus time $(\log ($ hours +1$))$ for the yellow abdominal markings of Syritta pipiens. Pixels were measured from UV photos and 19 specimens were included. Results are significant $\left(\chi^{2}{ }_{1}=13.747, \mathrm{p}<0.001\right)$. 18 
Figure 6. Average pixel value of red (A), green (B), and blue (C) versus the age of specimen for the yellow abdominal markings of Eurimyia lineatus. Pixel values were measured from visible photos and 29 specimens of various ages were included.

Figure 7. Average pixel brightness value versus the age of specimen for the ultraviolet reflecting yellow abdominal markings of Eurimyia lineatus. Pixel brightness values were measured from UV photos and 29 specimens of various ages were included. 20

Figure 8. Average number of red (A), green (B), and blue (C) pixels versus the age of specimen for the yellow abdominal markings of Syritta pipiens. Pixels were measured from visible photos and 44 specimens of various ages were included.

Figure 9. Average pixel brightness value versus the age of specimen for the ultraviolet reflecting yellow abdominal markings of Syritta pipiens. Pixel brightness values were measured from UV photos and 44 specimens of various ages were included. Results are significant $\left(\mathrm{R}^{2}=0.1635, \mathrm{~F}(1,42)=8.21, \mathrm{p}<0.01\right)$. 22

Figure 10. The mean UV colour strength score for of model(s) versus the mean UV colour strength score for the associated mimic for all four body regions. Results are marginally nonsignificant for head and legs, but significant for thorax and abdomen regions (head: $\mathrm{T}_{\mathrm{B}}(78)=0.156, \mathrm{p}=0.064$; legs: $\mathrm{T}_{\mathrm{B}}(78)=0.186, \mathrm{p}=0.057$; thorax: $\mathrm{T}_{\mathrm{B}}(78)=0.224, \mathrm{p}=0.01 ;$ abdomen: $\left.\mathrm{T}_{\mathrm{B}}(78)=0.419, \mathrm{p}<0.001\right)$ 38 
Figure 11. The average squared difference between the UV colour strength scores of a mimic and models. Each mimic species was compared to its own model(s) and to nonmodels. Results are significant $(\mathrm{t}(79)=-3.492, \mathrm{p}<0.001)$.

Figure 12. Two examples of the different types of UV colour. A) Cuticle colour (yellow in the human visible spectrum). B) Pile colour (white in the human visible spectrum)... 40

Figure 13. Averaged reflectance spectra for yellow thorax and abdominal colour and black thorax and abdominal colour for six species of hoverfly: A) Anasimyia lunulatus (1), B) Eristalis arbustorum (5), C) Eupeodes americanus or pomus (1), D) Eurimyia lineatus (1), E) Parasyrphus genualis (2), F) Platycheirus nearcticus (1)..................... 41

Figure 14. Averaged reflectance spectra for the yellow abdominal colour and the black abdominal colour of two species of hoverfly: A) Chalcosyrphus nemorum (2), B) Syritta pipiens (5). 42

Figure 15. Visible and ultraviolet photos of A) Lejops vittatus, B) Anasimyia lineata and their bee model C) Coelioxys inermis. 44 


\section{List of Appendices}

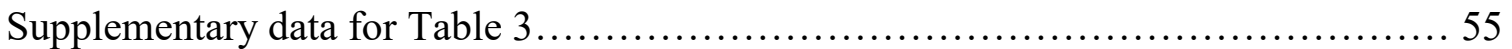




\section{Introduction}

This thesis focuses on ultraviolet (UV) colouration in hoverflies and its potential role in hoverfly mimicry. I will therefore begin by briefly introducing the key topics of my thesis: UV vision, UV colouration, and mimicry. In the chapter that follows this short introduction, I present a systematic survey of the extent to which UV vision and colour has been accounted for in behavioural research in the last year (2015). I then go on to present data on how the colours of pinned insect specimens change over time, and the extent to which hoverfly mimics resemble their putative hymenopteran models in the UV.

Animal colouration has evolved for a wide variety of purposes including sexual selection, thermoregulation, camouflage, and predator defense (Burtt, 1981). Because colour is such an integral part of the world around us it is easy to forget that our view of colour is entirely subjective. Humans are trichromatic: this means we have three cone cell types in our eyes that allow us to see wavelengths of light from $400-700 \mathrm{~nm}$ (Cronin et al., 2014). This so called "visible light" contains all the colours of the rainbow from red to violet. However, many other animals possess the ability to see wavelengths of light outside the visible spectrum, including infrared light (wavelengths $>700 \mathrm{~nm}$ ) and ultraviolet (UV) light (wavelengths $<400 \mathrm{~nm}$; Osorio and Vorobyev, 2008). This means that these animals can effectively see a different rainbow of colours than humans. For example, most insects are also trichromatic but have their wavelength sensitivity shifted to the left. This means that they are able to see UV light but have difficulty detecting reds (Briscoe and Chittka, 2001; Figure 1). Birds are tetrachromatic, with four photoreceptor 
types that allows them to see a broader rainbow that includes all human visible colours (including red) and UV (Hart and Hunt, 2007; Figure 1).
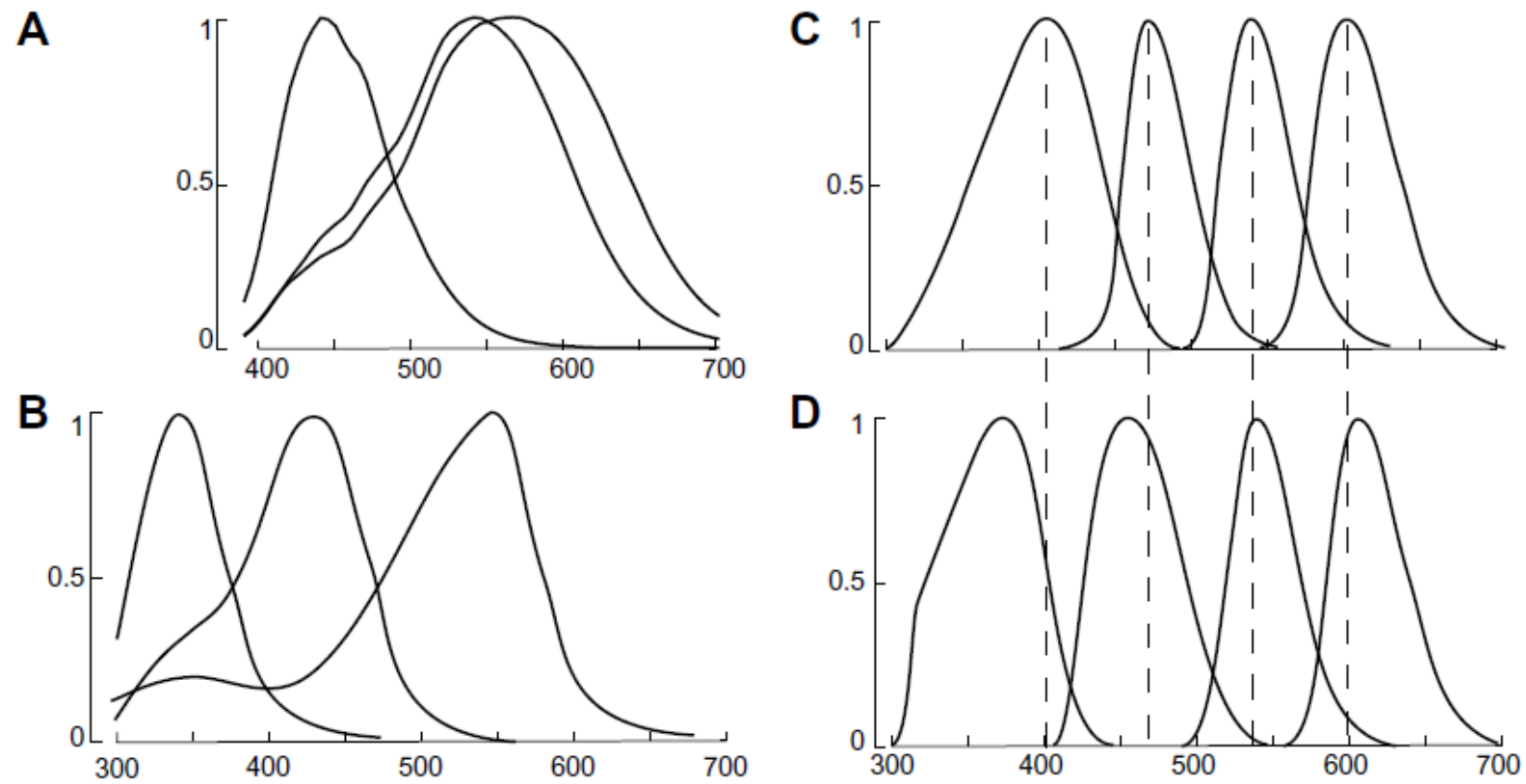

Figure 1. Normalized photoreceptor spectral sensitivities of: (A) human; (B) honeybee; (C) pigeon; (D) starling. $\mathrm{X}$-axis is wavelength of light, $\mathrm{y}$-axis is percent absorption. Taken from Osorio and Vorobyev, 2008.

In fact, the ability to see UV light is found in so many animal groups that it is more accurate to consider humans as "the odd ones out" (due to our lack of UV sensitivity) than it is to consider the ability to see UV as something special (Osorio and Vorobyev, 2008). An animal that can see UV will see colours that humans cannot. A flower which appears blue to humans, for example, will either be UV-blue (if UV reflective) or blue and UV absorbing to a UV sensitive animal. 
UV is a colour, and so like other colours it can be manufactured structurally and with pigments (Parker, 2000). Pigments are molecules that absorb specific wavelengths of light, but they are named for the wavelengths they do not absorb (Johnsen, 2012). A red pigment will therefore absorb all wavelengths of light except for the longer wavelengths associated with red (approx. 650 - $750 \mathrm{~nm}$; Johnsen, 2012). However, contrary to popular belief, pigments will actually appear black and reflect no light unless they have a structural layer beneath them that is reflective or contain another substance that scatters light (Johnsen, 2012). Because of this, ultraviolet markings must be structural, but can also be paired with a variety of pigments. This means that any "visible" colour can also potentially reflect UV wavelengths.

The existence of UV sensitive vision means that UV markings can be used for inter- and intra-species communication, just like visible colours (Silberglied, 1979). Although UV colour is not special in any way, ignoring it can lead to incorrect conclusions. I will therefore begin my thesis by discussing the ubiquity of UV colour and UV vision in animals and the importance of considering UV in studies that involve animals.

My next step will be to test whether preserved insect specimens can be used when studying insect colour (including UV colour). Preserved specimens can potentially provide an excellent source of data and many collections include large numbers of specimens of widely varying ages. However, in order to measure the colouration of dead and preserved specimens we must ensure that they accurately represent the colours of living individuals. So far, a number of studies have examined colour change over time in 
museum specimens of birds (McNett and Marchetti, 2005; Armenta et al., 2008; Doucet and Hill, 2009), but to my knowledge no such study has examined colour changes in insects. Therefore I will determine whether both visible and UV colour changes over short (months) and long (decades) periods of time in hoverflies (Diptera: Syrphidae). My null hypothesis is that visible and UV colours do not change over time in hoverflies.

Determining whether insect colour fades over time is vital for interpreting the data in my final chapter where I will be testing whether hoverfly mimics resemble their putative hymenopteran models in the UV. Hoverflies are Batesian mimics of bees and wasps, meaning that they are harmless species that mimic the appearance and/or behaviour of defended species (Ruxton, 2004). One of the unsolved mysteries of Batesian mimicry is the existence of imperfect mimics (Kikuchi and Pfennig, 2013). On first reflection, one might assume that mimics should evolve to resemble their models as closely as possible; however many mimics are seemingly easily distinguishable from their models to human eyes. Hoverflies provide an excellent example of this phenomenon, since species range from imperfect to perfect mimics (Penney et al., 2012). There are a number of hypotheses that attempt to explain the existence of imperfect mimics (Table 1). 
Table 1. Hypotheses for the persistence of imperfect mimicry (adapted from Kikuchi and Pfennig, 2013).

\section{Hypothesis \\ Eye-of-the-beholder \\ Developmental constraints}

Chase-away

Relaxed selection

Mimetic breakdown

Perceptual exploitation

Satyric mimicry

Multiple models

Multiple predators

Kin selection

Character displacement

Ugly duckling

\section{Summary}

Imperfect mimics appear "imperfect" to humans but predators perceive these mimics in a different way.

Mimics are unable to achieve perfection due to constraints to their evolution (such as insufficient genetic variation).

Mimetic perfection is unattainable since models are also continually evolving to escape their mimics.

Imperfect mimics have the same fitness as perfect mimics and so are under no pressure to increase their mimetic fidelity.

Mimicry is no longer an effective strategy and so mimetic traits are beginning to disappear through natural selection.

Mimics exploit the innate perceptual bias that causes predators to avoid models, perfect mimicry is not necessary.

Imperfect mimics confuse predators by possessing a combination of model traits in an unexpected context.

Mimics have multiple models and so their appearance is a mixture of traits that resemble each model.

Mimics are predated upon by generalist predators that avoid their model but also by specialist predators that target their model. Therefore the safest option is to imperfectly resemble a model to avoid both predator types.

Imperfect mimics increase the fitness of their kin by directing attacks away from more perfect mimics.

Imperfect mimics are a compromise between predator-mediated selection (favours perfect mimics) and competitively-mediated selection (favouring imperfect mimics).

A poor mimic (a "duck") has simply been paired with the wrong model and is actually an excellent mimic (a "swan") once the correct model is identified. 
One of these hypotheses is "the eye of the beholder". As I previously stated, many animals have very different visual systems than humans. This hypothesis states that the existence of "imperfect" mimics is therefore due to our skewed perception (resulting from our different visual system) and that actually the mimics are much more perfect in the eyes of their predators (Bennett et al., 1994). This hypothesis may be an appropriate explanation for imperfect mimicry in hoverflies since the evolution of mimicry is driven by predators and it is likely that most, if not all, hoverfly predators are capable of detecting UV (Table 2).

Table 2. A selection of potential hoverfly predators that possess UV sensitive vision.

\begin{tabular}{lll}
\hline Animal group & Examples & References \\
\hline Birds & Blackbird, Blue tit, Starling & Hart and Hunt, 2007 \\
Reptiles & Gecko, Anole, Lizard & $\begin{array}{l}\text { Loew, 1994; Loew et al., } \\
\text { 2002; Pérez i de Lanuza and } \\
\end{array}$ \\
& Font, 2014 \\
Fmphibians & & Govardovskii and Zueva, \\
& & $1974 ;$ Silberglied, 1979 \\
Arachnids & Jumping spider, & Yamashita and Tateda, \\
& Crab spider & $1976 ;$ Defrize et al., 2011 \\
Insects & Dragonfly & Briscoe and Chittka, 2001 \\
\hline
\end{tabular}

So far, measurements of colour in a number of hoverfly species have not detected much UV reflection (Taylor et al., 2016) however since there are over 6000 species it is possible that there is still UV reflecting colour in this group. Assessments of mimetic fidelity in hoverflies are often done by humans (Golding et al., 2005), although pigeons have also been used (Dittrich et al., 1993; Green et al,. 1999). These assessments using 
pigeons were in part an attempt to assuage the eye-of-the-beholder hypothesis; however since pigeons have a violet sensitive cone, not an ultraviolet sensitive cone, they may not be able to perceive much UV reflection (Hart and Hunt, 2007). It is therefore possible that UV reflection in hoverflies increases their resemblance to their models and I hypothesize that hoverfly mimics will resemble their models in the UV spectrum. 


\section{Chapter 1: Ultraviolet vision and colour}

\section{Introduction}

Ultraviolet (UV) wavelengths of light are invisible to the human eye, yet these wavelengths are seen and utilized by many other species. The discovery of UV vision, and UV colour, in animals has meant that research which involves animals with UV colour or vision should take UV into account. Despite the fact that the importance of UV has been asserted multiple times over the years (Silberglied, 1979; Cuthill and Bennett, 1993; Church et al., 2004; Stevens et al., 2007) a significant amount of current research still fails to account for it. In order to estimate how often UV is neglected I conducted a survey of articles published in Animal Behaviour, Behavioural Ecology, and Behavioural Ecology and Sociobiology in 2015. My first step was to find papers with a focus on animals known to have UV vision. Then, out of this smaller subset, I selected papers that involved assumptions about how colour is perceived by receivers. I classified each paper in terms of whether they had (i) measured colour appropriately (by including all reflected wavelengths detectable by the receiver), (ii) adequately controlled for colour when using artificial or dead animals, or when altering live animal color, and (iii) used appropriate indoor artificial lighting (did not exclude certain wavelengths of light). Each paper received a label of "UV" (UV was accounted for) or "No UV" (UV was not accounted for) based on the appropriateness of their methods. My survey found that 31 of the 63 articles did not take all possible steps to account for UV (Table 3; references in Supplementary Data). The sample data therefore suggests that there is still significant room for improvement. 
Table 3. A summary of the methods of 63 articles published in three top animal behaviour journals in the year 2015. The articles chosen focused on animals with ultraviolet (UV) vision, and made assumptions about how colours are perceived by receivers. UV - UV vision and colour was accounted for; No UV - UV colour and vision was not accounted for; Measured - the study measured or assessed animal colour; Models - the study used artificial models, video, or altered live animal colouration; Lighting - the study used artificial lighting. Note: a study may appear in the table more than once, although a study cannot be both "UV" and "No UV". A full list of the papers can be found in Supplementary Data.

\begin{tabular}{|c|c|c|}
\hline Animal Behaviour & Behavioral Ecology & $\begin{array}{c}\text { Behavioral Ecology } \\
\text { and Sociobiology }\end{array}$ \\
\hline No UV & No UV & No UV \\
\hline
\end{tabular}

\section{Birds}

Measured

Model

Lighting

$\begin{array}{ll}3 & 1 \\ 1 & 3 \\ 0 & 0\end{array}$

5
0
2

1
2
0

2

2

\section{Reptiles/amphibians}

\begin{tabular}{|c|c|c|c|c|c|}
\hline Measured & 1 & 0 & 3 & 1 & 2 \\
\hline Model & 1 & 0 & 1 & 0 & 1 \\
\hline Lighting & 0 & 0 & 0 & 0 & 0 \\
\hline
\end{tabular}

\section{Fishes}

$\begin{array}{lllllll}\text { Measured } & 1 & 1 & 2 & 3 & 0 & 3 \\ \text { Model } & 0 & 1 & 0 & 2 & 0 & 0 \\ \text { Lighting } & 1 & 1 & 2 & 3 & 0 & 1\end{array}$

\section{Insects/arachnids}

\begin{tabular}{lcccccc} 
Measured & 2 & 1 & 1 & 0 & 1 & 0 \\
Model & 4 & 1 & 4 & 1 & 0 & 1 \\
Lighting & 0 & 1 & 0 & 0 & 1 & 0 \\
Total & 14 & 10 & 20 & 13 & 8 & 11 \\
\hline
\end{tabular}




\section{The ubiquity of ultraviolet colour and vision}

Measuring the photoreceptor sensitivities of animals is a fairly new practice (Kelber et al., 2003) and yet UV vision has already been found in a large number of animals belonging to diverse taxa. The presence of UV sensitive photoreceptors is known to be widespread in birds and insects (Briscoe and Chittka, 2001; Hart and Hunt, 2007). Indeed, UV vision is the ancestral state for vertebrates and is known to persist in some species of mammals, reptiles, amphibians, and fishes (Hunt et al., 2001). The pervasiveness of UV vision means that, as with visible colours, animals can use UV colouration for purposes ranging from sexual selection to predator defense (Bennett et al., 1994; Church et al., 2004; Crothers and Cummings, 2013). Even if a species itself is incapable of seeing UV, its predators, prey, or competitors may have UV vision. Reflected UV wavelengths $(300-400 \mathrm{~nm})$ can be combined with any reflected visible wavelengths of light $(400-700 \mathrm{~nm})$ to create a range of UV colours. This means that any visible colour, including black, can be UV reflective and examples of UV reflective colours have been found in many animals (Table 4). Although fewer studies have attempted to discern the role that UV colours play, a number of functions for the UV colours in a variety of animals have been proposed and occasionally tested (Table 4). 
Table 4. Examples of human visible colours $(400-700 \mathrm{~nm})$ which also reflect light in the UV spectrum $(300-400 \mathrm{~nm})$ in a variety of animal species, and their proposed roles.

\begin{tabular}{|c|c|c|c|}
\hline Visible colour & Animal example & Proposed role of colour & Reference \\
\hline \multirow[t]{2}{*}{ Violet } & $\begin{array}{l}\text { Female migrant hawker } \\
\text { dragonfly (Aeshna } \\
\text { mixta) }\end{array}$ & $\begin{array}{l}\text { Sexual } \\
\text { dimorphism/selection, } \\
\text { species recognition }\end{array}$ & Harris et al., 2011 \\
\hline & $\begin{array}{l}\text { Blue-necked tanager } \\
\text { (Tangara cyanicollis) }\end{array}$ & Species recognition & $\begin{array}{l}\text { Finger and } \\
\text { Burkhardt, } 1994\end{array}$ \\
\hline \multirow[t]{4}{*}{ Blue } & $\begin{array}{l}\text { Male hairy dragonfly } \\
\text { (Brachytron pratense) }\end{array}$ & $\begin{array}{l}\text { Sexual } \\
\text { dimorphism/selection, } \\
\text { species recognition }\end{array}$ & Harris et al., 2011 \\
\hline & $\begin{array}{l}\text { Tent caterpillar } \\
\text { (Malacosoma } \\
\text { americanum) }\end{array}$ & Unknown & Byers, 1975 \\
\hline & $\begin{array}{l}\text { Male blue tit (Parus } \\
\text { caeruleus) }\end{array}$ & $\begin{array}{l}\text { Sexual } \\
\text { dimorphism/selection }\end{array}$ & Hunt et al., 1998 \\
\hline & $\begin{array}{l}\text { Lilford's wall lizard } \\
\text { (Podarcis lilfordi) }\end{array}$ & Species recognition & $\begin{array}{l}\text { Pérez i de Lanuza } \\
\text { and Font, } 2011\end{array}$ \\
\hline \multirow[t]{4}{*}{ Green } & $\begin{array}{l}\text { Weevil (Exophthalmos } \\
\text { annulonotatus) }\end{array}$ & Crypsis or aposematism & $\begin{array}{l}\text { Pope and Hinton, } \\
1977\end{array}$ \\
\hline & $\begin{array}{l}\text { Grey shoulder-knot } \\
\text { caterpillar (Lithophane } \\
\text { ornitopus) }\end{array}$ & Aposematism & Church et al., 1998 \\
\hline & $\begin{array}{l}\text { Gouldian finch } \\
\text { (Cloebia gouldiae) }\end{array}$ & Species recognition & $\begin{array}{l}\text { Finger and } \\
\text { Burkhardt, } 1994\end{array}$ \\
\hline & $\begin{array}{l}\text { Bluehead wrasse } \\
\text { (Thalassoma } \\
\text { bifasciatum) }\end{array}$ & Unknown & Losey et al., 1999 \\
\hline \multirow[t]{2}{*}{ Yellow } & $\begin{array}{l}\text { Beetle (Glycyphana } \\
\text { horsfieldi) }\end{array}$ & Species recognition & Hinton, 1973 \\
\hline & European greenfinch & Species recognition & Finger and \\
\hline
\end{tabular}


Puerto Rican crested anole (Anolis cristatellus)

Orange

Red

Purple

Brown

Grey

Black
Male orange sulphur butterfly (Colias eurytheme)

Rainbow lorikeet (Trichoglossus haematodus)

Checkerboard wrasse (Halichoeres hortulanus)

Scarlet ibis (Eudocimus ruber)

Gouldian finch (Cloebia gouldiae)

Brown lory (Chalcopsitta duivenbodei)

Eggs of the red-chested cuckoo (Cuculus solitarius)

Ambon damselfish (Pomacentrus amboinensis)

Herring gull (Larus Unknown argentatus)

Danaid Eggfly butterfly (Hypolimnas misippus)

Black lory (Chalcopsitta atra)

Unknown
Sexual

dimorphism/selection

Fleishman et al., 1993

Sexual dimorphism/

Silberglied and selection, species recognition

Taylor, 1973

Sexual selection

Hausmann et al., 2003

Losey et al., 1999

Unknown

Species recognition

Species recognition

Finger and

Burkhardt, 1994

Species recognition

Finger and

Burkhardt, 1994

Cherry and

Bennett, 2001

Species recognition

Siebeck et al., 2010

Silberglied, 1973

Species recognition

Finger and

Burkhardt, 1994 


\begin{tabular}{|c|c|c|c|}
\hline \multirow[t]{5}{*}{ White } & $\begin{array}{l}\text { Yellow fever mosquito } \\
\text { (Aedes aegypti) }\end{array}$ & Disruptive colouration & Hinton, 1973 \\
\hline & $\begin{array}{l}\text { Longhorn beetle } \\
\text { (Calothyrza pauli) }\end{array}$ & Crypsis or aposematism & $\begin{array}{l}\text { Pope and Hinton, } \\
1977\end{array}$ \\
\hline & $\begin{array}{l}\text { Buff-tailed bumblebee } \\
\text { (Bombus terrestris) }\end{array}$ & Aposematism & Stelzer et al., 2010 \\
\hline & $\begin{array}{l}\text { Peppered moth (Biston } \\
\text { betularia) }\end{array}$ & Crypsis & Majerus et al., 2000 \\
\hline & $\begin{array}{l}\text { Eggs of the cape robin } \\
\text { (Cossypha caffra) }\end{array}$ & Species recognition & $\begin{array}{l}\text { Cherry and } \\
\text { Bennett, } 2001\end{array}$ \\
\hline \multirow[t]{3}{*}{$\begin{array}{l}\text { Gold and } \\
\text { Silver }\end{array}$} & $\begin{array}{l}\text { Mantis fly (Ochthera } \\
\text { mantis) }\end{array}$ & Unknown & Steinly et al., 1978. \\
\hline & $\begin{array}{l}\text { Male jumping spider } \\
\text { (Cosmophasis } \\
\text { umbratica) }\end{array}$ & $\begin{array}{l}\text { Sexual (and juvenile- } \\
\text { adult) } \\
\text { dimorphism/selection }\end{array}$ & Lim and $\mathrm{Li}, 2006$ \\
\hline & $\begin{array}{l}\text { Dark-edged splitfin } \\
\text { (Girandinichthys } \\
\text { multiradiatus) }\end{array}$ & $\begin{array}{l}\text { Sexual selection, species } \\
\text { recognition }\end{array}$ & $\begin{array}{l}\text { Garcia and Burt de } \\
\text { Perera, } 2002\end{array}$ \\
\hline
\end{tabular}

The prevalence of UV vision and colour means that any study that involves measuring the colour of dead or alive animal specimens, or uses real or artificial animals in experiments must consider the visual system of the receiver, whether it be a predator, prey, competitor, or conspecific. Studies that disregard UV will provide less meaningful results since the colours used or described will not be equivalent to the colours perceived by the animal in question.

\section{Conclusions}

The extensive presence of UV photoreceptors in animal visual systems, and the numerous examples of UV colour in animals, shows that UV colour is as important as any other 
visible colour. Studies that quantify colour, or even qualitatively describe or compare colour patterns must take UV colour into account. Descriptions of colour should not reflect our view of them, but instead should be tailored to the purpose of the colour. For example, a red beetle with UV reflection may appear red to humans, be UV-red to birds and only UV reflective to conspecifics who cannot perceive long wavelengths. Studies that attempt to emulate colour should manufacture models which match their appearance in the UV and visible wavelengths, while experiments that examine animal behaviour should ensure that the spectrum of light is representative. Studies that involve animal colouration may have misleading results if they do not consider the visual system of the receiver. 


\section{Chapter 2: Measuring insect colour}

\section{Introduction}

Although the measurement of live individuals is often ideal, it can be difficult or impossible in practice and can restrict the number of individuals that can be sampled. Therefore, dead animal specimens can be a vital resource when studying animal colouration. Animal colour can be the result of pigments, structural colour, or both, and over time these structures or compounds can break down, resulting in a change in the hue or intensity of colour (Parker, 2000; McNamara et al., 2012; Johnsen, 2012). For example dragonfly (Odonata) colours fade after death and can change if the insect's metabolism is affected (such as in cold conditions; Mitchell and Lasswell, 2000). Therefore, any studies of colouration in these species should be restricted to live specimens. However, there is little research that examines how colours change over time in insect taxa. A number of studies have examined the effect of time and preservation on bird feathers and have found that colours can fade over time (McNett and Marchetti, 2005; Armenta et al., 2008; Doucet and Hill, 2009). However, the extent of the fade and the portion of the spectrum most affected varied from study to study, and most studies concluded that preserved birds can be used to represent live avian colouration. In fact, in their study on long tailed manakins (Chiroxiphia linearis), Doucet and Hill (2009) stated that "variation in reflectance in a single population of wild birds often matched or exceeded variation in museum specimens spanning the entire geographic distribution of long-tailed manakins over a period of more than one hundred years". My goal was to determine whether visible and ultraviolet colour changed over time in insects and specifically in hoverflies 
(Diptera:Syrphidae), a common and abundant group known for their mimicry of bees and wasps. I hypothesized that hoverfly colour does not change significantly after death, and over longer periods of preservation such as decades.

\section{Methods}

Photography

I collected 92 live hoverflies from May $24^{\text {th }} 2015$ to September $2^{\text {nd }} 2015$ at one of four locations in Canada: Rigaud, QC ( $\left.45^{\circ} 28^{\prime} \mathrm{N}, 74^{\circ} 18^{\prime} \mathrm{W}\right)$, Queen's University Biological

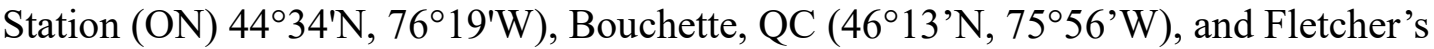
wildlife garden in Ottawa, $\mathrm{ON}\left(45^{\circ} 23^{\prime} \mathrm{N}, 75^{\circ} 42^{\prime} \mathrm{W}\right)$. I collected a total of 23 hoverfly species (and some hoverflies only identifiable to genus). I captured insects using nets and placed them in plastic tubes before transporting them back to the laboratory. I then pinned the live insects and photographed them in both visible and ultraviolet (UV) light using a Nikon D70 camera with an El Nikkor 80mm lens and a Baader U UV filter (Baader Planetarium, Germany: 310-390nm UV transmission). This camera has been used in previous research involving UV (Stelzer et al., 2010; D. Kikuchi, personal communication) and the El-Nikkor lens is sensitive to wavelengths $320 \mathrm{~nm}$ and higher (Verhoeven and Schmitt, 2010). The light source was a MTD70 EYE colour arc bulb (70W 1.0A power source, www.eyelighting.co.uk) which has a D65 spectrum (the same spectrum as sunlight). This allowed me to take visible and UV photos with the same lighting. I pinned insects to a grey, UV absorbing background and took four photos: one visible photo of the dorsal side, one UV photo of the dorsal side, one visible photo of the right side and one UV photo of the right side. I took the visible photos without a filter and 
used an exposure time of 13 milliseconds and then added the filter for the UV photos which had an exposure time of six seconds (since less UV light is available). I positioned the camera on a tripod to reduce movement (Figure 2).

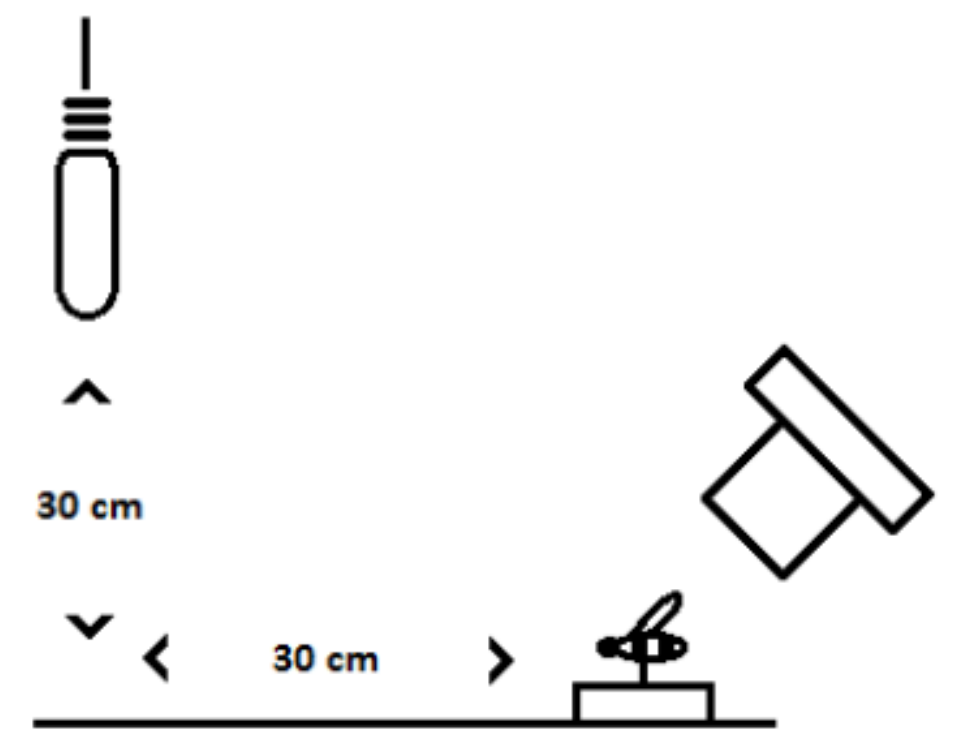

Figure 2. The photography set up. The camera is on the right side of the diagram and is pointing at the specimen (tripod not shown) while the light is on the top left.

I took all photos in RAW format (other formats will compress photo data causing data to be lost or altered). I also included a spectralon $99 \%$ reflective standard and a small scale bar in each photo. Some insects moved their wings too rapidly for the long exposure time and in those cases I removed one or both wings. Once an insect was photographed alive I immediately placed it in either a cyanide tube or the freezer (treatments were assigned randomly) and left it for approximately 20 minutes, causing death. I then photographed it again using the same methods. Afterwards I photographed the same insect another seven 
times: at 30 minutes after death, 24 hours, seven days, 14 days, 30 days, 90 days, and 180 days. This gave me a total of nine photographs for each specimen.

Photo analysis

Of the collected hoverflies, 13 species and two genera (unable to identify to species) were considered to have UV reflective colour on the basis of bright markings being visible in the UV photographs (Table 5).

Table 5. The species or genus ID, number of specimens, and presence/absence of UV colour for the 92 hoverflies collected. The CNC collection numbers for all specimens can be found in the Specimen data excel file.

\begin{tabular}{lll}
\hline Species or genus & $\begin{array}{l}\text { Number of } \\
\text { specimens }\end{array}$ & UV reflective colour present \\
& & somewhere on body \\
\hline Allograpta obliqua & 2 & yes \\
Anasimyia lunulatus & 1 & yes \\
Chalcosyrphus nemorum & 2 & yes \\
Dasysyrphus intrudens complex & 1 & no \\
Epistrophe nitidicollis & 1 & no \\
Eristalis arbustorum & 5 & yes \\
Eristalis tenax & 1 & no \\
Eristalis transversa & 4 & no \\
Eupeodes & 6 & yes \\
Eurimyia lineatus & 1 & yes \\
Helophilus fasciatus & 1 & no \\
Parasyrphus genualis & 2 & yes \\
Parhelophilus laetus & 1 & yes \\
Platycheirus immarginatus & 1 & yes \\
Platycheirus nearcticus & 2 & yes \\
Platycheirus obscurus & 1 & yes \\
Platycheirus & 1 & yes \\
Sericomyia chrysotoxoides & 1 & no \\
Sphaerophoria & 1 & no \\
Sphaerophoria novaeangliae & 1 & no \\
Sphiximorpha willistoni & 1 & no \\
Syritta pipiens & 20 & yes \\
Syrphus ribesii & 1 & yes \\
Toxomerus geminatus & 2 & no \\
& & \\
& &
\end{tabular}


\begin{tabular}{lll} 
Volucella evecta & 1 & no \\
Xylota quadrimaculata & 1 & yes \\
\hline
\end{tabular}

No specimens had obvious changes (to the human eye) in ultraviolet or visible colour over the six months. I chose to measure the colour of Syritta pipiens over time since I had the largest number of specimens for this species and it had some of the brightest UV reflecting yellow colour on its abdomen. I used 19 out of the 20 specimens since the standard was not visible in one of the photos for specimen CNC649401. Using the dcraw plugin in ImageJ (which converts RAW files to smaller 16 bit files without losing or altering photo data; Schneider et al., 2012; Coffin, 2015) I selected five to ten square patches of the yellow abdominal markings on the fly's cuticle in both the visible and UV photos. I also selected an area of the reflection standard in each photo. For the UV photos I recorded the average pixel brightness value $((\mathrm{R}+\mathrm{G}+\mathrm{B}) / 3))$ and for the visible photos I recorded the average pixel value of each colour channel $(\mathrm{R}, \mathrm{G}, \mathrm{B})$. I then used the values for the standard to standardize these measurements by dividing each pixel value for the standard by 255 (the maximum pixel value possible in each colour channel) and then dividing the average measured pixel value by the resulting proportion. Standardization is important since it accounts for any slight differences in brightness between photos that could affect pixel values.

Since the time period over which the collected insects were photographed was quite short (six months), I also photographed insects in the Canadian National Collection of Arachnids, Nematodes and Insects (Ottawa, ON, same methods as previous) and measured their colour. This allowed me to test whether there was an effect of specimen 
age on colour. I selected Eurimyia lineatus and Syritta pipiens (Figure 3) based on the large number of specimens available in the collection and the fact that they were among those species I collected live that had UV reflecting colour. I photographed all collection specimens that were collected in the province of Ontario.

\section{A)}

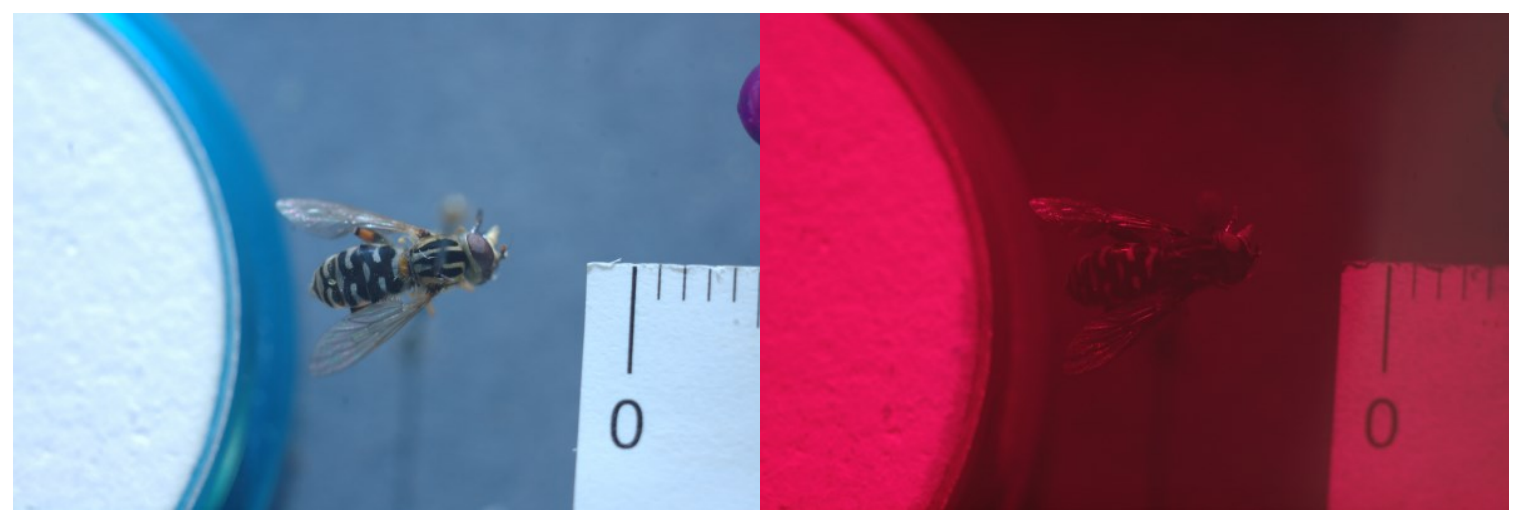

B)

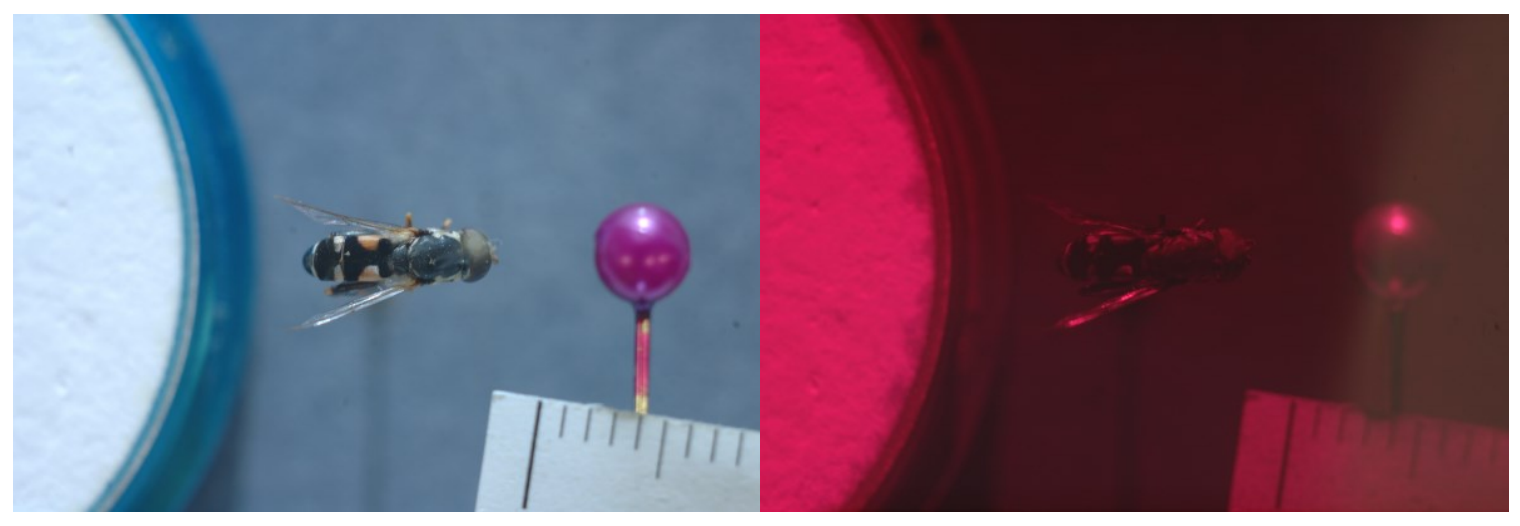

Figure 3. Visible and ultraviolet photographs of Eurimyia lineatus (A) and Syritta pipiens (B).

I undertook the same methods when measuring the colour of the $\mathrm{CNC}$ specimens. All the CNC specimens used had been collected in Ontario. 
Statistical analysis

Models were fitted in R 3.3.2 (R Core Development Team 2016). My first step was to determine whether visible colour changed over a short period of time (months) in Syritta pipiens. I therefore tested whether the average pixel value of each colour (red, green, blue) in the visible photos changed over time. Including specimen ID as a random effect was crucial for the analysis, because by controlling for specimen ID it allowed us to quantify any colour change within each specimen. I also included killing method (freezing or cyanide) as a fixed factor. Multivariate linear regression could not be employed with the inclusion of a random effect, so instead I fitted three linear mixed models (one for each colour channel) with the average pixel value of red/green/blue as the response variable. Each photo was assigned a time in hours ( 0 hours (alive) to 4320 hours ( 6 months $))$ and $\log ($ time +1$)$ was included as the continuous predictor to ensure normality and homogeneity of variance while specimen ID was included as a random effect variable and killing method was included as a fixed factor. Analysis of deviance was used to test whether we could reject the NH that the colour component did not vary over time. To test whether UV colour changed over time in S. pipiens I fitted the same linear mixed model but with the average pixel brightness value in the UV photos as the response variable. Due to the fact that there is no UV colour channel in a camera the UV reflectance in a photograph is a combination of $\mathrm{R}, \mathrm{G}$ and $\mathrm{B}$ pixel values.

Next, I determined whether the visible and UV colour of museum specimens of Eurimyia lineatus and S. pipiens differed due to age, with time spanning decades. Here the same 
specimen was not repeatedly measured, so specimen ID was not treated as a random factor.

To test whether the average pixel value of red, green, and blue changed over time in the visible photos I performed a MANOVA with the average pixel value of red, green and blue as the response variable and time in years as the predictor. To test whether the average pixel brightness value changed over time in the UV photos I fitted a linear regression with the average number of pixels as the response variable and time in years as the predictor.

\section{Results}

In the analysis of the insect specimens over six months there was significant change in the average pixel value of red (analysis of deviance, $\left.\chi^{2}{ }_{1}=15.464, \mathrm{p}<0.001\right)$, green $\left(\chi^{2}{ }_{1}\right.$ $=9.544, \mathrm{p}<0.01)$, and blue $\left(\chi^{2}{ }_{1}=4.965, \mathrm{p}<0.01\right)$ in visible photos of Syritta pipiens taken over a six month period (Figure 4). There was also significant change in the average pixel brightness value $\left(\chi^{2}{ }_{1}=13.747, \mathrm{p}<0.001\right)$ in the UV photos taken over the same period (Figure 5). This change was in the form of the following increases in average pixel value per unit of time $(\log ($ hours +1$))$ : red, 1.05; blue, 0.666 ; green, 0.336 ; and UV, 0.851 .

There was no significant effect of killing method on average red $\left(\chi^{2}{ }_{1}=0.824, \mathrm{p}=\right.$ $0.364)$, green $\left(\chi^{2}{ }_{1}=0.053, \mathrm{p}=0.819\right)$ or blue $\left(\chi^{2}{ }_{1}=0.047, \mathrm{p}=0.828\right)$ pixel values or on average pixel brightness values $\left(\chi^{2}{ }_{1}=0.153, \mathrm{p}=0.696\right)$. 
The analysis of the museum specimens showed that there was no significant difference in the average pixel values of red, green, or blue in the visible photos of E. lineatus (Pillai's Trace $=0.197, \mathrm{~F}(1,3)=2.123, \mathrm{p}=0.122 ;$ Figure 6) and S. pipiens $($ Pillai's Trace $=0.080$, $\mathrm{F}(1,3)=1.251, \mathrm{p}=0.303$; Figure 8) over decades, or in the average pixel brightness value in the UV photos of E. lineatus $\left(\mathrm{R}^{2}=0.043, \mathrm{~F}(1,27)=1.207, \mathrm{p}=0.282\right.$; Figure 7). However the analysis of S. pipiens did show a significant decrease in average pixel brightness value in the UV photos $\left(\mathrm{R}^{2}=0.1635, \mathrm{~F}(1,42)=8.21\right.$, $\mathrm{p}<0.01$; Figure 9). The S. pipiens analysis contained specimens that were over 100 years old, and an additional analysis that removed specimens over 100 years old found no significant change $\left(\mathrm{R}^{2}=\right.$ $0.035, \mathrm{~F}(1,35)=1.252, \mathrm{p}=0.271)$. 
A)

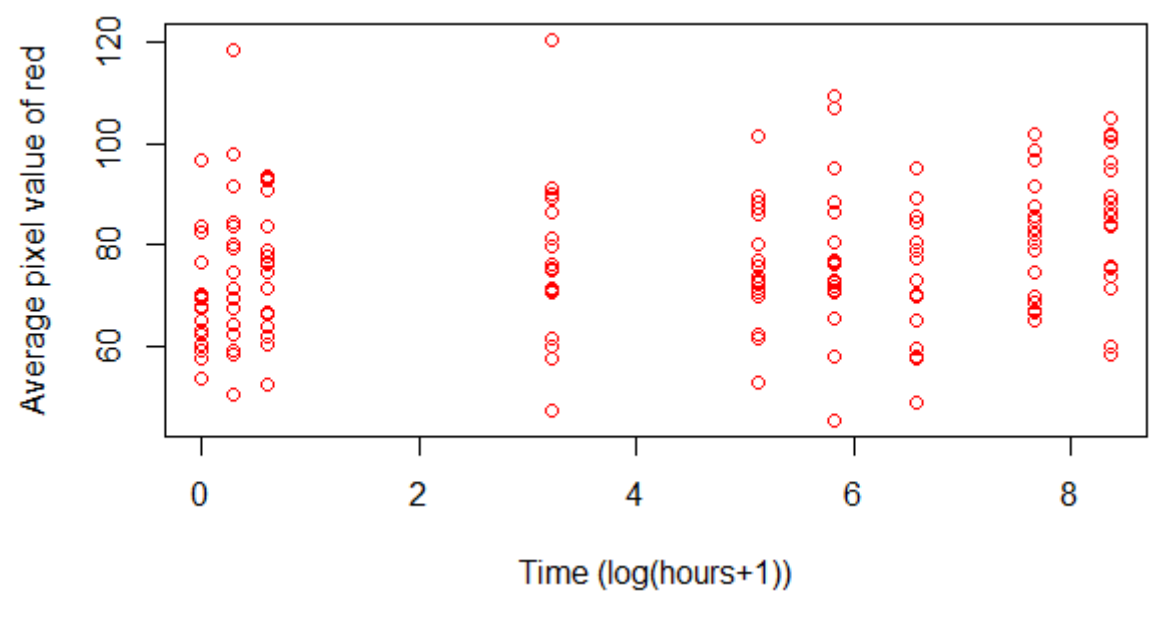

B)
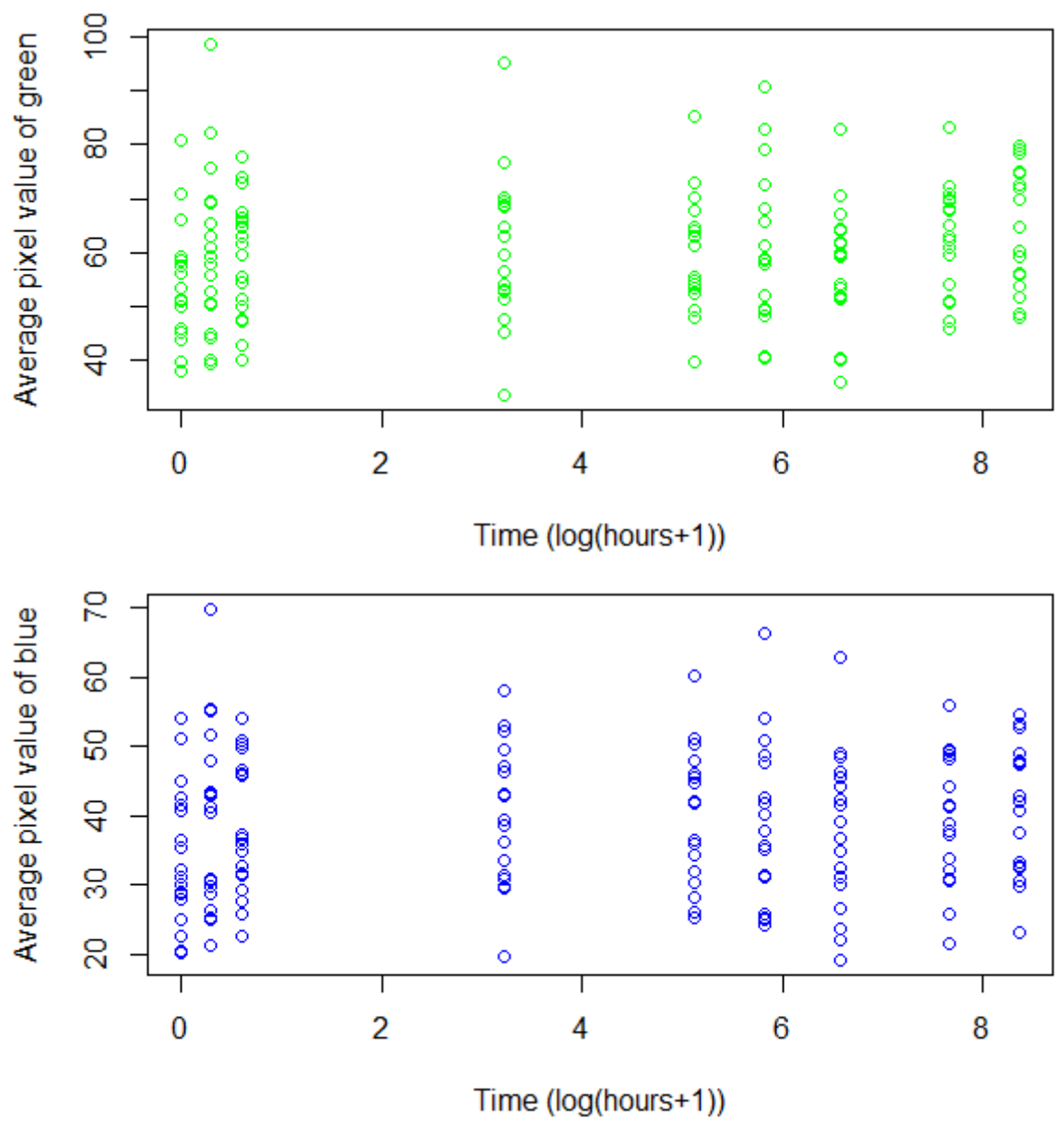

Figure 4. Average pixel value of red (A), green (B), and blue (C) versus time $(\log ($ hours +1$))$ for the yellow abdominal markings of Syritta pipiens. Pixel values were measured from visible photos and 19 specimens were included. Results are significant (red: analysis of deviance, $\chi^{2}{ }_{1}=15.464, p<0.001$, green: $\chi_{1}{ }_{1}=9.544, p<0.01$, and blue: $\chi^{2}{ }_{1}=4.965, p<0.01$ ). 


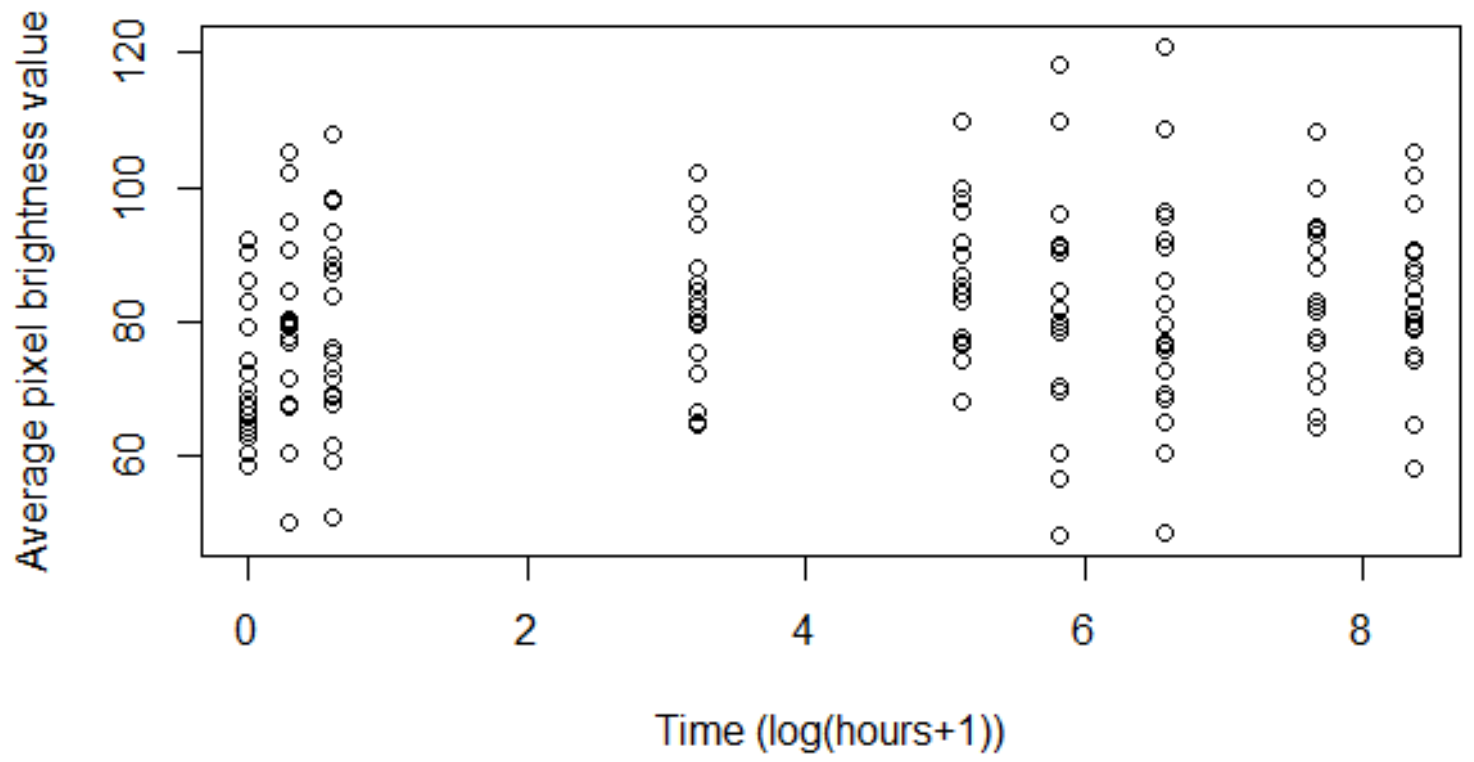

Figure 5. Average pixel brightness value versus time $(\log ($ hours +1$))$ for the $U V$ yellow abdominal markings of Syritta pipiens. Pixels were measured from UV photos and 19 specimens were included. Results are significant $\left(\chi^{2}{ }_{1}=13.747, \mathrm{p}<0.001\right)$. 
A)

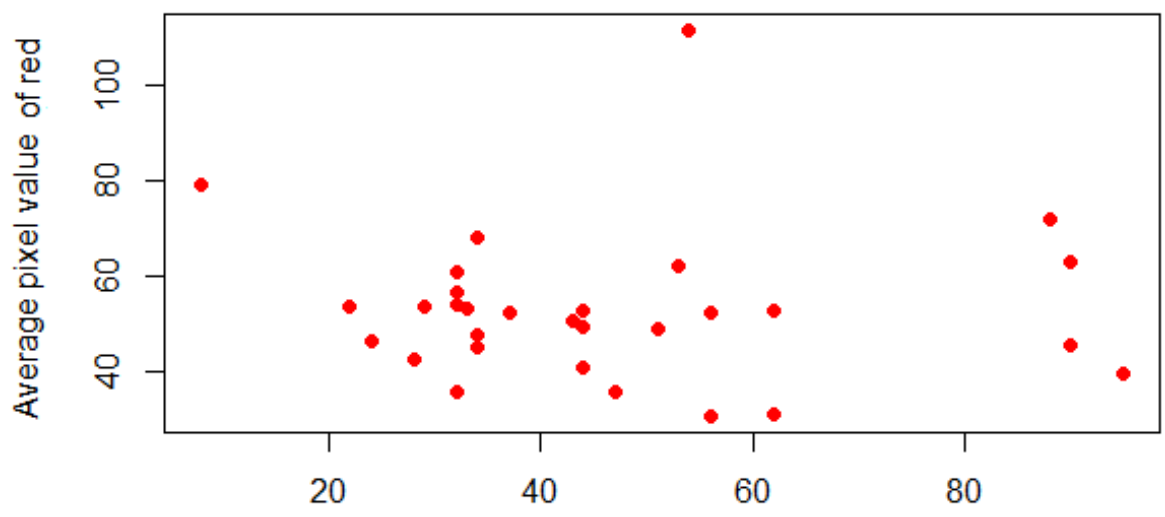

B)

Age of specimen (years)

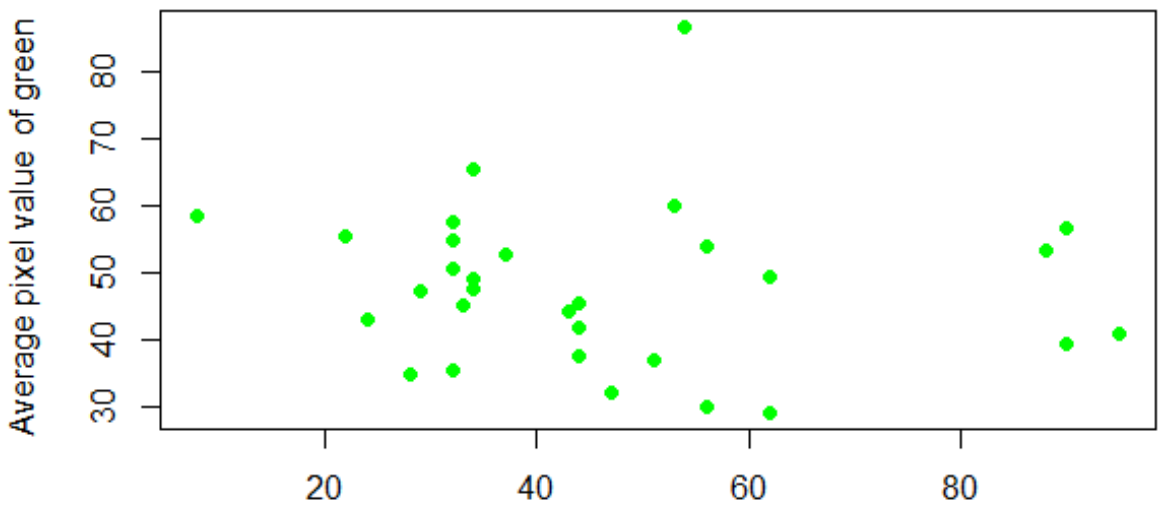

Age of specimen (years)

C)

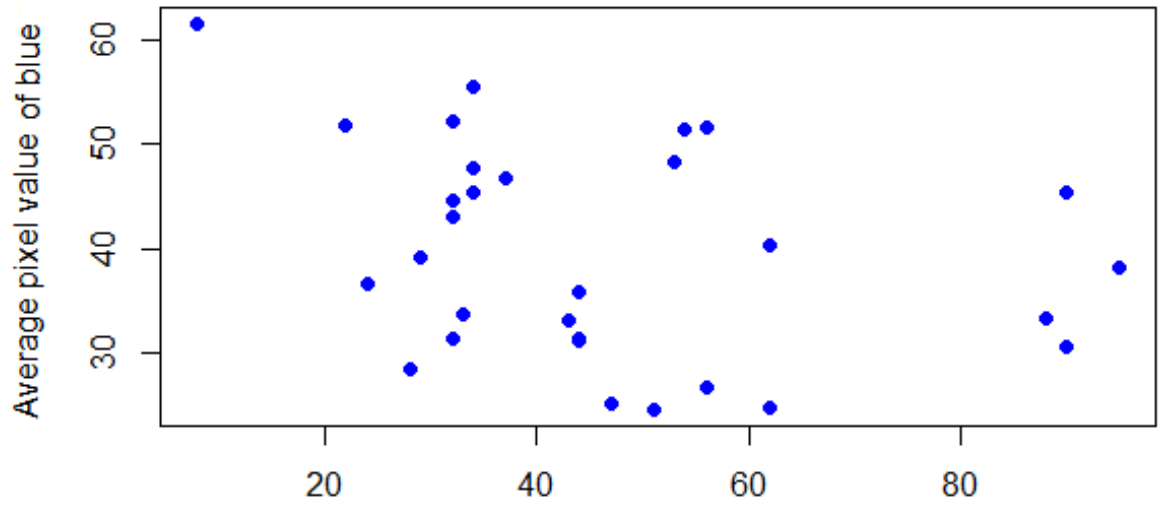

Age of specimen (years)

Figure 6. Average pixel value of red (A), green (B), and blue (C) versus the age of specimen for the yellow abdominal markings of Eurimyia lineatus. Pixel values were measured from visible photos and 29 specimens of various ages were included. 


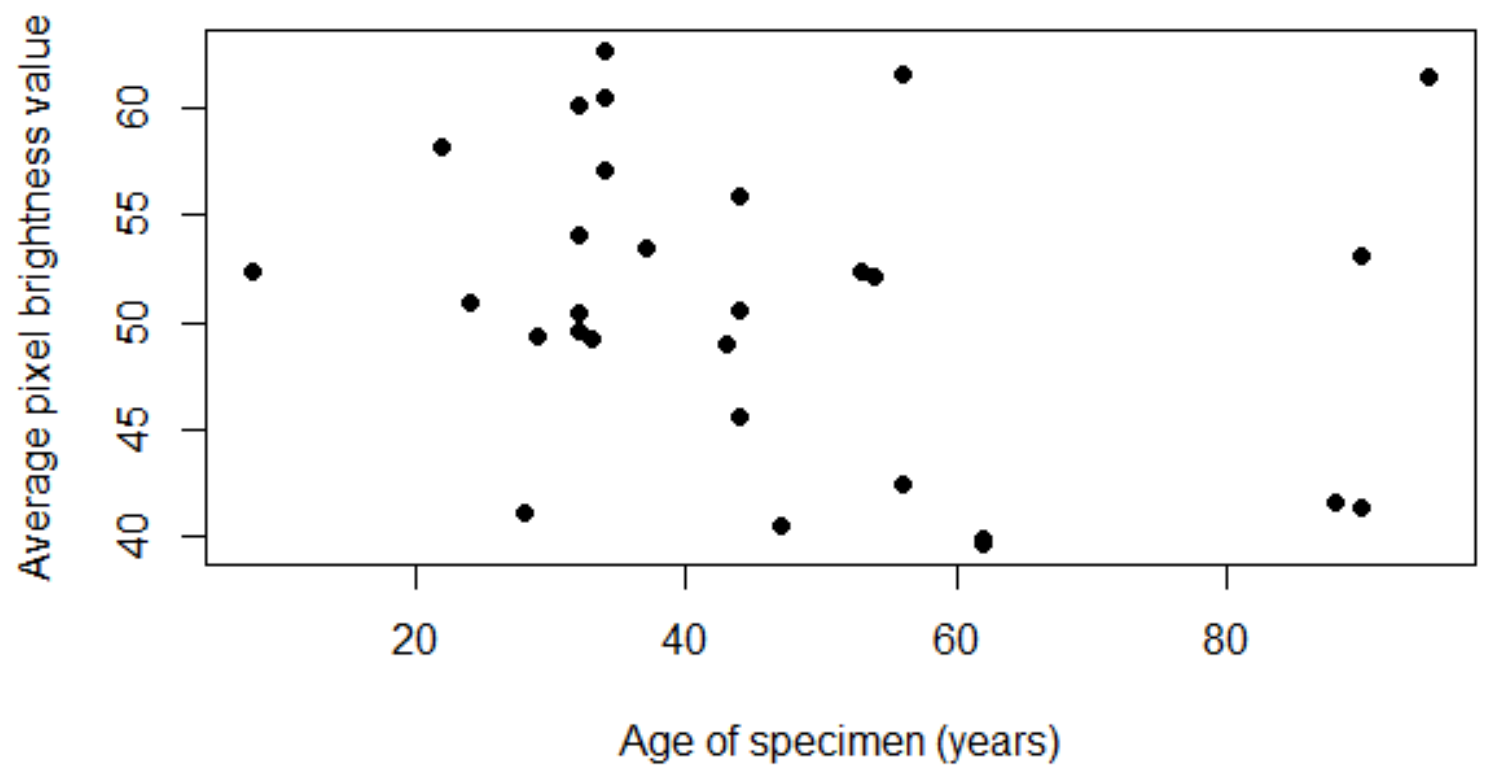

Figure 7. Average pixel brightness value versus the age of specimen for the ultraviolet reflecting yellow abdominal markings of Eurimyia lineatus. Pixel brightness values were measured from UV photos and 29 specimens of various ages were included. 
A)

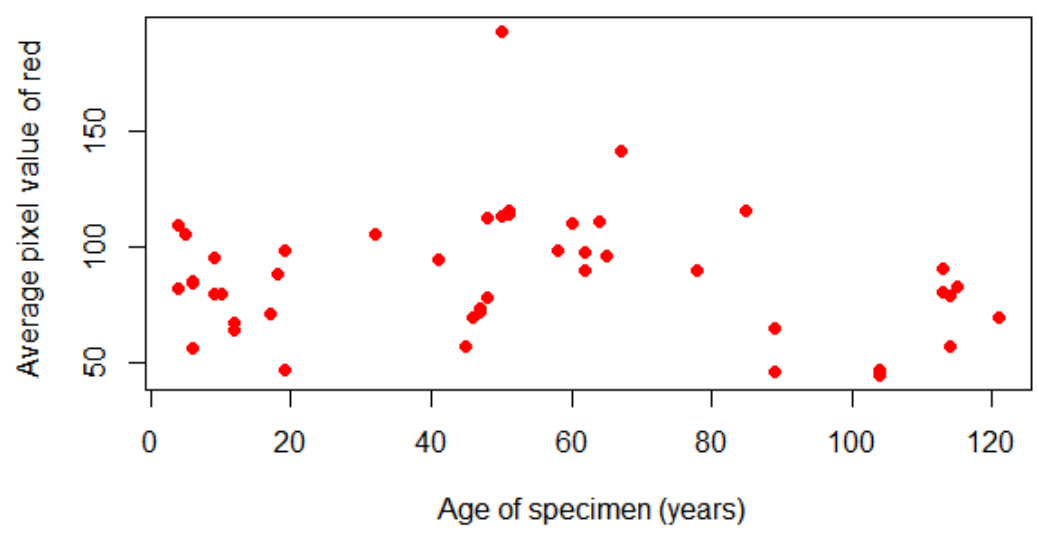

B)

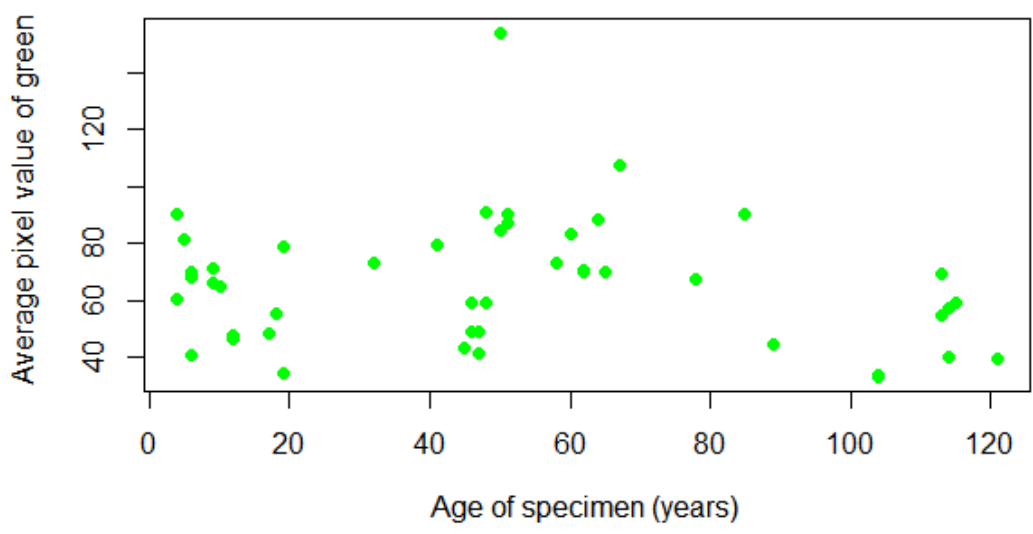

C)

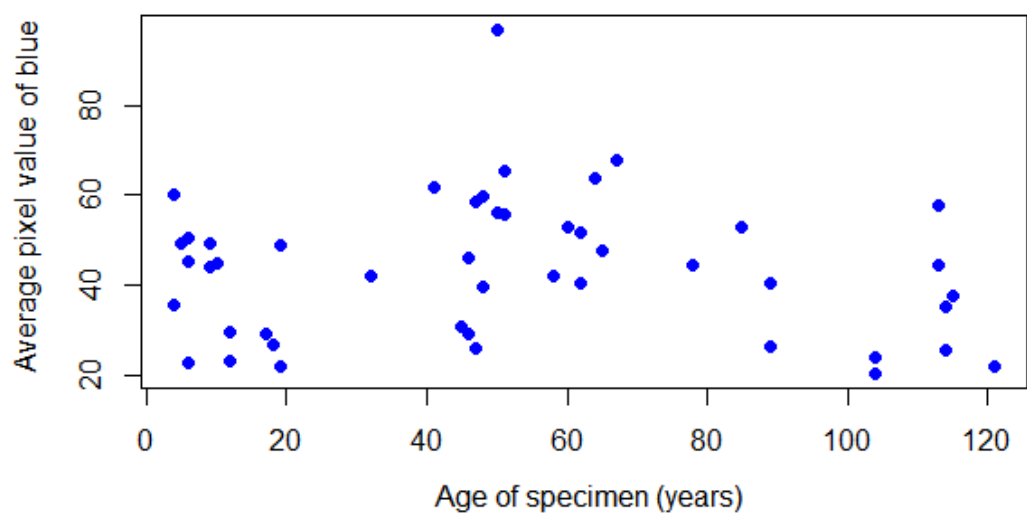

Figure 8. Average number of red (A), green (B), and blue (C) pixels versus the age of specimen for the yellow abdominal markings of Syritta pipiens. Pixels were measured from visible photos and 44 specimens of various ages were included. 


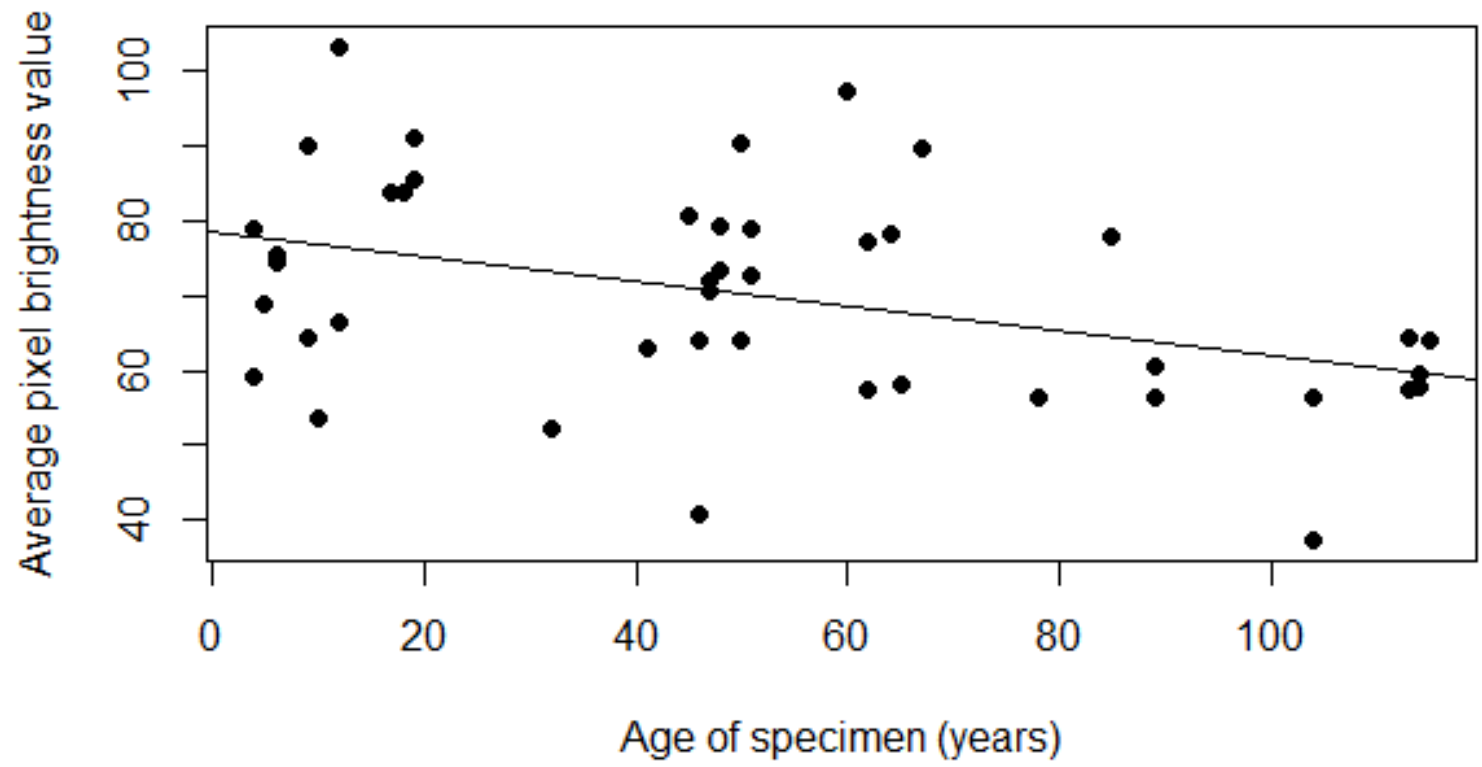

Figure 9. Average pixel brightness value versus the age of specimen for the ultraviolet reflecting yellow abdominal markings of Syritta pipiens. Pixel brightness values were measured from UV photos and 44 specimens of various ages were included. Results are significant $\left(R^{2}=0.1635, F(1,42)=8.21\right.$, $\mathbf{p}<\mathbf{0 . 0 1 )}$.

\section{Discussion}

Interestingly, the average pixel value $(\mathrm{R}, \mathrm{G}, \mathrm{B})$ in the visible photos and the average pixel brightness value (UV) in the UV photos of Syritta pipiens increased over the short term. This means that the collected specimens' visible and UV colour increased in brightness (as opposed to fading) over the six month period after death. A decrease in both visible and UV colour would indicate that pigments and/or structures were breaking down while a decrease in visible colour paired with an increase in UV colour could indicate that yellow pigments were degrading while the UV reflecting structures stayed intact. Therefore less UV wavelengths would be absorbed by the pigments and UV colour would increase while yellow faded. An increase in the brightness of both visible and UV 
colour means it is most likely that an additional coating (perhaps the cement or waxy layer on the outer surface of the epicuticle, Gullan and Cranston, 2010) was degrading, allowing more light to reach the pigments or colour reflecting structures beneath. This would lead to brighter yellow and UV colour. Although the increase in average pixel value (R, G, B) and average pixel brightness value (UV) was statistically significant I believe it is unlikely to have a strong effect on how the colours of dead hoverfly specimens are perceived when compared to living specimens. This is because the increase in average pixel value (and average pixel brightness value) was very small (one pixel value or less per unit of time $(\log ($ hours +1$))$. In addition, the analysis of colour change over decades found that average pixel value and average pixel brightness value did not change significantly in visible or UV photos of Eurimyia lineatus (over 95 years) or in the visible photos of Syritta pipiens (over 121 years). The average pixel brightness value of the UV photos of S. pipiens did significantly decrease over time when all specimens were included in the analysis, but when specimens over 100 years old were excluded it was no longer significant. This means that UV colour does fade over time but that it is slow and gradual enough that it only becomes apparent when very old specimens are included. The fact that visible and UV colour increase in brightness over a short period of time after death but stay stable over much longer periods means it is likely that whatever coating is degrading does so fairly quickly after death. These results bolster the use of insect specimens in colour research since it is likely that other insects, such as hymenopterans, use the same types of pigments or physical structures to create colours (Chapman, 1998). Although the killing methods of the CNC specimens were not known, there was no effect of killing method on the colour of specimens I collected therefore it is 
unlikely to be an important consideration when using museum specimens. McNett and Marchetti's 2005 study on colour change in museum specimens of wood warblers found that brightness decreased with age, with UV colours showing a greater decrease over time. One likely cause for this greater colour fade is the presence of bacteria on bird feathers. Birds have a wide array of bacteria on their feathers and while some types are beneficial, other types such as keratinolytic bacteria can degrade feathers and alter hue and brightness (Goldstein et al., 2004; Shawkey et al., 2007). Many of the CNC hoverfly specimens I used were likely collected or stored in ethanol at some point (a common collection technique) which would help kill off any bacteria present on their bodies at the time of collection.

I was unable to determine whether the visible yellow colour or the UV colour was due to pigments (possibly pterins or ommachromes) or structural colour in the two species of hoverfly that I measured (Chapman, 1998). Determining the basis of the colour in these species will help elucidate whether the consistency of colour over time is due to a lack of degradation of structure or of pigment molecules. Interestingly, there was considerable variation in colour and overall brightness between specimens of the same species (variance due to specimen ID: red, 80.51; green, 85.62; blue, 83.22; UV, 115.78). This was despite the fact that many specimens were collected in the same location and even on the same day. UV colour in jumping spiders is known to be affected by age and feeding history (Lim and Li, 2007), while UV colour in butterflies can be affected by stressors, and environmental factors (Kemp et al., 2006; Pecháček et al., 2014). This could explain the variation found in individual hoverflies of the same species that were caught on the 
same day and/or at the same location. The large variation between individuals means that it is important that measurements of a species' colour use multiple specimens. It is also important to note that my samples came from a well-regulated collection and were stored in ideal conditions. It is possible that this contributed to consistency in colour over long periods of time. This study is an important step in determining the accuracy of using insect collections in colour research. However due to the huge diversity of insects I would urge that future research focus on other species in a variety of orders. 


\section{Chapter 3: Ultraviolet mimicry in hoverflies}

\section{Introduction}

One of the puzzles of Batesian mimicry is the existence of imperfect mimics (Kikuchi and Pfennig, 2013). A variety of hypotheses have been proposed to explain the existence of these imperfect mimics, including the "eye of the beholder" hypothesis (Cuthill and Bennett, 1993). This hypothesis is based on the fact that different organisms have different sensory systems and different cognitive functioning and it posits that a mimic who might seem imperfect to us could in fact be a perfect, or at least a passable, mimic to its predators. Batesian mimicry is a defensive strategy used to protect an organism from predation, which means its evolution is driven by predators. Therefore, when assessing the fidelity of a mimic we need to consider the sensory system of its predators.

One of the most obvious differences between humans and other predators is our colour vision. Humans are trichromatic and can see only visible wavelengths of light (400 - 700 $\mathrm{nm})$, but many other taxa can also see ultraviolet (UV) wavelengths $(300-400 \mathrm{~nm})$. UV sensitive photoreceptors have been found in a wide variety of animal groups including some mammals, birds, reptiles, amphibians, and arachnids (Govardovskii and Zueva, 1974; Hart and Hunt, 2007; Defrize et al., 2011; Pérez i de Lanuza and Font, 2014). UV sensitivity has also been discovered in every insect species examined so far (Briscoe and Chittka, 2001). 
Hoverflies (Diptera:Syrphidae) are a well-known example of Batesian mimicry and provide an excellent study system due to their abundance and apparent wide range of mimetic perfection: from imperfect to perfect (Penney et al., 2012). Some hoverfly species are also polymorphic, with different forms mimicking different models. So far however, the majority of assessments of mimetic fidelity in hoverflies have only examined mimic and model appearances using visible colours (Howarth et al., 2000; Howarth and Edmunds, 2000; Holloway et al., 2002; Edmunds and Reader, 2014; Penney et al., 2014). A recent study by Taylor et al. (2016) also found little UV reflection in a number of mimic and model species when using a spectrophotometer. Despite this, it is clear that hoverfly predators are capable of seeing UV colour. Birds, which are likely the main predator of hoverflies (Edmunds, 2008), are known to use UV signals when foraging and attacking prey (Burkhardt, 1982; Olofsson et al., 2010) and UV colour has been found in many other insect groups so far (Table 6), including bumblebees (Stelzer et al., 2010) which are well-known models of hoverflies. Given that UV colour is widespread in insects and the majority of insect predators can see UV I hypothesize that hoverfly mimics will match their models in the UV spectrum. 
Table 6. Examples of UV reflective colours in a number of insect orders.

\begin{tabular}{lll}
\hline Order & UV reflective colour & Refences
\end{tabular}

Coleoptera

White, metallic blue, yellow, copper, red

Hinton, 1973; Pope and Hinton, 1977

Diptera

White, silver, gold

Hinton, 1973; Steinly et al., 1978

\section{Hemiptera larvae}

White

Hinton, 1977

Hymenoptera

White

Stelzer et al., 2010

Lepidoptera

larvae

White, blue, green

Byers, 1975; Church et al., 1998

Lepidoptera

adults

Odonata

$\begin{array}{ll}\text { White, blue, green, orange, red, } & \begin{array}{l}\text { Brues, 1941; S } \\ \text { Majerus, } 2000\end{array}\end{array}$

White, violet, blue, green, iridescent blue and green, yellow

Robey, 1975; Harris et al., 2011

\section{Methods}

Photography

I chose to photograph mimic and model groups that had been previously been compiled by mimicry experts (see below). This allowed me to test whether independent classifications of mimics and models created using visible light were supported by UV data. I compiled my list of mimic species and their proposed models using three separate publications (Howarth et al., 2000; Howarth and Edmunds, 2000; Edmunds and Reader, 
2014). All species were European, but some are also found in North America. Hoverfly mimic species were paired with one or more bee or wasp model species and some mimics shared the same models. I photographed specimens from the CNC (Canadian National Collection of Insects, Arachnids, and Nematodes, Ottawa) with the exception of several hymenopteran species that were borrowed from York University (ON, Canada). I photographed 76 hoverfly species (three of which had multiple varieties or morphologies) and 67 hymenopteran species. When possible, I would photograph five individuals from each species. If more than five individuals of a species were available I would select specimens that were intact and with wing placement such that the wings were not obscuring any body parts. I also preferentially selected specimens that had been collected in Europe. This was because the species I chose are Palearctic and to ensure that mimics and models were from roughly the same location. All photography equipment and methods used are the same as those stated in Chapter 2. I recorded specimen details, such as ID number, sex, age, location, and killing method for all specimens photographed (if such data was available). Although a spectrophotometer can provide detailed spectra, photographs are useful for rapid screening of large numbers of specimens. Also a spectrophotometer can only be used to measure specific points, while a photograph will elucidate patterns. The two approaches are therefore complementary.

I used the photographs to categorize each specimen as having UV reflecting colour anywhere on its body (1) or not (0). I then used volunteers to assign UV colour strength scores for all those specimens I had judged to have UV reflecting colour. A separate UV colour score was solicited for each main body region: head, thorax, abdomen, and legs. I showed four volunteers photos of the specimens and asked them to rank the strength of the UV reflecting 
colour as 0 (none), 1 (weak) or 2 (strong) for each body region. I presented all hoverfly photos first followed by all Hymenoptera photos (in alphabetical order) to prevent any potential association between mimics and models. The human volunteers assayed 445 specimens in this way. This enabled me to get an average value of UV strength for each body section.

Statistical analysis of photograph data

All models were fitted in R 3.3.2 (R Core Development Team 2016). I first calculated the mean UV strength score for each body region of every species of mimic and model, treating species as the unit of replication. Since the data was non-normal I used Kendall's tau to determine whether there was a significant relationship between the mean UV colour strength of mimics and their models for each body region (Spearman's rho cannot handle tied data points), with species as the replicate. Next I calculated the mean squared difference in UV colour strength between members of a mimic (species 1) and specimens of its own models (species 2$)$ for each body region $\left(\left(\mathrm{H}_{1}-\mathrm{H}_{2}\right)^{2}+\left(\mathrm{T}_{1}-\mathrm{T}_{2}\right)^{2}+\left(\mathrm{A}_{1}-\mathrm{A}_{2}\right)^{2}+\left(\mathrm{L}_{1}-\right.\right.$ $\left.\mathrm{L}_{2}\right)^{2}$ ); if there were multiple model species then the mean value of all model strength scores was used) and the mean difference in UV colour strength between a mimic and all non-models (i.e. excluding its own model(s)). I then used a paired t-test to determine whether mimics were more or less different to their own models than to other (non-) models.

\section{Microspectrophotometry}

In addition to photographing specimens, I also sent off the collected hoverfly specimens to have their colour spectra measured with a microspectrophotometer by Dr. Nate Morehouse at 
the University of Pittsburgh (Pittsburgh, PA, USA). I collected hoverflies from May $24^{\text {th }}$ 2015 to September $2^{\text {nd }} 2015$ in four different areas: Rigaud, QC $\left(45^{\circ} 28^{\prime} \mathrm{N}, 7^{\circ} 18^{\prime} \mathrm{W}\right)$, Queen's University Biological Station (ON) 44³4'N, 76²19'W), Bouchette, QC $\left(46^{\circ} 13^{\prime} \mathrm{N}, 75^{\circ} 56^{\prime} \mathrm{W}\right)$, and Fletcher's wildlife garden in Ottawa, ON (45²3' $\left.\mathrm{N}, 75^{\circ} 42^{\prime} \mathrm{W}\right)$. I then photographed the same specimens in UV to determine which species had UV reflecting colour (more detailed methods were described in Chapter 2). I chose eight different species with UV reflecting colour to be measured. The UV reflective yellow areas and the UV absorbing black areas on the following numbers of each species were then measured using the microspectrophotometer: Anasimyia lunulatus (1), Chalcosyrphus nemorum (2), Eristalis arbustorum (5), Eupeodes americanus or pomus (1; females of these species cannot currently be distinguished), Eurimyia lineatus (1), Parasyrphus genualis (2), Platycheirus nearcticus (1), Syritta pipiens (5).

In order to relate the human UV strength scores to the spectra I summed the area under the spectral curves for the UV portions of the spectra $(300-400 \mathrm{~nm})$. This gave me an UV brightness value for both black and UV reflecting yellow areas of the hoverflies' thoraxes and abdomens. I then had the same four volunteers as I had used earlier rank the UV colour strength of all the areas that were measured with the microspectrophotometer based this time on UV photos. The volunteers were instructed to use the same ranking as before: 0 (none), 1 (weak) or 2 (strong). This allowed me to test whether humans were able to accurately predict the amount of UV reflection based on photographs. 
Statistical analysis of microspectrophotometry data

My primary aim here was to evaluate whether human-based evaluations based on photographs could be related to the micro spectrophotometer UV brightness

measurements. To do this, I fitted two general linear mixed models to the compiled data with $\log (\mathrm{UV}$ brightness value) as a continuous response variable, body part (thorax or abdomen) as a binomial predictor (fixed factor) and human volunteer ID and specimen ID as random effect variables. To test whether human scores reflected microspecrophotometer UV values, I also included human UV strength score as a continuous predictor in the first model and dropped it from a second model to compare the fit. I did not include visible colour as a predictor variable in either model since I was only interested in the UV portion of the spectrum. I then used Akaike's Information Criterion (AIC) to determine the best model.

\section{Results}

Photography

The majority of the hoverfly and hymenopteran species I photographed had markings which were visible in the UV photographs: 60 out of the 80 hoverfly species/varieties had UV reflecting colour, while 44 out of the 67 hymenopteran species had UV reflecting colour (Table 7). 
Table 7. Hoverfly mimics and their proposed hymenopteran models. Blue - bee species; Red - wasp species; Bolded - UV reflecting colour present in at least one body section. Mimic and model pairings were compiled from: Howarth et al., 2000; Howarth and Edmunds, 2000; Edmunds and Reader, 2014.

Mimic

Lejops (Anasimyia) contracta

Eurimyia lineatus (Anasimyia lineata)

Lejops (Anasimyia) transfugus

Sericomyia (Arctophila) superbiens

Baccha elongata

Blera fallax

Xylota (Brachypalpoides) lenta

Brachypalpus (Brachypalpus) valgus

(Brachypalpus laphriformis)

\begin{tabular}{ll}
\hline Caliprobola speciosa & Dolichovespula sylvestris \\
\hline Chalcosyrphus (Xylotomima) nemorum & Ectemnius continuus \\
\hline Cheilosia albipila & Andrena apicata \\
\hline Cheilosia chrysocoma & Andrena fulva \\
\hline Cheilosia fraterna & Lasioglossum albipes, L. fratellum \\
\hline Cheilosia corydon (Cheilosia grossa) & Andrena nigrodenea \\
\hline Cheilosia illustrata & Andrena cineraria, Bombus pratorum, B. \\
& sylvarum \\
\hline Cheilosia impressa & Lasioglossum albipes, L. fratellum \\
\hline Cheilosia mutabilis & Lasioglossum albipes, L. fratellum \\
\hline Cheilosia nebulosa & Lasioglossum albipes, L. fratellum \\
\hline Cheilosia pagana & Lasioglossum albipes, L. fratellum \\
\hline Cheilosia tarditas (Cheilosia scutellata) & L. albipes, L. fratellum \\
\hline Cheilosia vernalis & Lasioglossum albipes, L. fratellum \\
\hline Chrysotoxum arcuatum & Vespula vulgaris, Dolichovespula norvegica. \\
\hline
\end{tabular}

\section{Proposed models}

Epeolus variegatus, Epeolus cruciger

Coelioxys inermis

Epeolus variegatus, Epeolus cruciger

Bombus pascuorum, B. humilis, B. muscorum

Trypoxylon attenuatum, T. clavicerum

Osmia bicolor, Osmia aurulenta

Astata boops

Apis mellifera

Dolichovespula sylvestris

Andrena nigrodenea

Andrena cineraria, Bombus pratorum, B.

Lasioglossum albipes, L. fratellum

Lasioglossum albipes, L. fratellum

Vespula vulgaris, Dolichovespula norvegica. 
Dolichovespula sylvestris, Vespula austriaca,

Vespula germanica, Vespula rufa

\begin{tabular}{|c|c|}
\hline Chrysotoxum bicinctum & Argogorytes mystaceus \\
\hline Chrysotoxum cautum & $\begin{array}{l}\text { Vespula vulgaris, Dolichovespula norvegica. } \\
\text { Dolichovespula sylvestris, Vespula austriaca, } \\
\text { Vespula germanica, Vespula rufa }\end{array}$ \\
\hline Criorhina asilica & Apis mellifera \\
\hline Criorhina berberina typical form & $\begin{array}{l}\text { Bombus pratorum, B. sylvarum B. pascuorum, } \\
\text { B. terrestris }\end{array}$ \\
\hline Criorhina berberina var. oxyacanthae & Bombus pascuorum, B. humilis, B. muscorum \\
\hline Criorhina floccosa & Bombus pascuorum, B. humilis, B. muscorum \\
\hline Criorhina ranunculi & $\begin{array}{l}\text { Bombus lapidarius, B. lucorum, B. ruderarius, } \\
\text { B. terrestris }\end{array}$ \\
\hline Dasysyrphus tricinctus & Nysson spinosus \\
\hline Doros profuges & Ancistrocerus antilope \\
\hline Epistrophe (Epistrophe) grossulariae & $\begin{array}{l}\text { Vespula vulgaris, Dolichovespula norvegica. } \\
\text { Dolichovespula sylvestris, Vespula austriaca, } \\
\text { Vespula germanica, Vespula rufa }\end{array}$ \\
\hline Epistrophe (Epistrophe) nitidicollis & $\begin{array}{l}\text { Vespula vulgaris, Dolichovespula norvegica. } \\
\text { Dolichovespula sylvestris, Vespula austriaca, } \\
\text { Vespula germanica, Vespula rufa }\end{array}$ \\
\hline Episyrphus (Episyrphus) balteatus & $\begin{array}{l}\text { Vespula vulgaris, Dolichovespula norvegica. } \\
\text { Dolichovespula sylvestris, Vespula austriaca, } \\
\text { Vespula germanica, Vespula rufa }\end{array}$ \\
\hline Eriozona (Eriozona) syrphoides & $\begin{array}{l}\text { Bombus pratorum, Bombus sylvarum, Bombus } \\
\text { terrestris }\end{array}$ \\
\hline Eristalis (Eoseristalis) arbustorum & Apis mellifera \\
\hline Eristalis (Eoseristalis) intricaria females & $\begin{array}{l}\text { Bombus terrestris, B. hortorum, B. jonellus, B. } \\
\text { lucorum, B. magnus, B. soroeensis, Psithyrus } \\
\text { barbutellus, P. bohemicus, P. vestalis }\end{array}$ \\
\hline
\end{tabular}




\begin{tabular}{|c|c|}
\hline Eristalis (Eoseristalis) intricaria & Bombus pratorum, B. sylvarum \\
\hline Eristalis (Eoseristalis) pertinax & Apis mellifera \\
\hline Eristalis (Eoseristalis) rupium & Apis mellifera \\
\hline Eristalis (Eristalis) tenax & Apis mellifera \\
\hline Eumerus strigatus & Osmia caerulescens, Hoplitis claviventris \\
\hline Eumerus tuberculatus & Osmia caerulescens, Hoplitis claviventris \\
\hline Ferdinandea cuprea & Andrena apicata \\
\hline Helophilus (Helophilus) hybridus & $\begin{array}{l}\text { Vespula vulgaris, Dolichovespula norvegica. } \\
\text { Dolichovespula sylvestris, Vespula austriaca, } \\
\text { Vespula germanica, Vespula rufa }\end{array}$ \\
\hline Helophilus (Helophilus) pendulus & $\begin{array}{l}\text { Vespula vulgaris, Dolichovespula norvegica. } \\
\text { Dolichovespula sylvestris, Vespula austriaca, } \\
\text { Vespula germanica, Vespula rufa }\end{array}$ \\
\hline Helophilus (Helophilus) trivittatus & $\begin{array}{l}\text { Vespula vulgaris, Dolichovespula norvegica. } \\
\text { Dolichovespula sylvestris, Vespula austriaca, } \\
\text { Vespula germanica, Vespula rufa }\end{array}$ \\
\hline Lejops (Lejops) vitattus & Coelioxys inermis \\
\hline Mallota (Mallota) cimbiciformis & Apis mellifera \\
\hline Merodon (Merodon) equestris & $\begin{array}{l}\text { Bombus terrestris, B. lucorum, B. muscorum, } \\
\text { B. pascuorum, B. ruderarius }\end{array}$ \\
\hline Microdon (Microdon) mutabilis & Anthophora furcata, Andrena chrysosceles \\
\hline Neoascia (Neoasciella) geniculata & $\begin{array}{l}\text { Stigmus solskyi, Crossocerus megacephalus, } C \text {. } \\
\text { ovalis, C. elongatulus, C. wesmaeli }\end{array}$ \\
\hline Neoascia (Neoasciella) interrupta & $\begin{array}{l}\text { Stigmus solskyi, Crossocerus megacephalus, } C \text {. } \\
\text { ovalis, C. elongatulus, C. wesmaeli }\end{array}$ \\
\hline Neoascia (Neoasciella) meticulosa & $\begin{array}{l}\text { Stigmus solskyi, Crossocerus megacephalus, } C \text {. } \\
\text { ovalis, C. elongatulus, C. wesmaeli }\end{array}$ \\
\hline Neoascia (Neoasciella) obliqua & $\begin{array}{l}\text { Stigmus solskyi, Crossocerus megacephalus, } C \text {. } \\
\text { ovalis, C. elongatulus, C. wesmaeli }\end{array}$ \\
\hline Neoascia (Neoascia) podagrica & Stigmus solskyi, Crossocerus megacephalus, $C$. \\
\hline
\end{tabular}




\begin{tabular}{|c|c|}
\hline & ovalis, C. elongatulus, C. wesmaeli \\
\hline Neoascia (Neoascia) tenur & $\begin{array}{l}\text { Stigmus solskyi, Crossocerus megacephalus, } C \text {. } \\
\text { ovalis, C. elongatulus, C. wesmaeli }\end{array}$ \\
\hline Orthonevra splendens & L. albipes, L. fratellum \\
\hline Parasyrphus annulatus & $\begin{array}{l}\text { Vespula vulgaris, Dolichovespula norvegica. } \\
\text { Dolichovespula sylvestris, Vespula austriaca, } \\
\text { Vespula germanica, Vespula rufa }\end{array}$ \\
\hline Parhelophilus frutetorum & Vespula rufa \\
\hline Pocota personata & Bombus terrestris \\
\hline Pyrophaena (Pyrophaena) granditarsa & $\begin{array}{l}\text { Nomada fabriciana, Andrena labiata, Andrena } \\
\text { marginata, Sphecodes spinulosus }\end{array}$ \\
\hline Rhingia (Rhingia) campestris & Andrena marginata, Sphecodes gibbus \\
\hline Scaeva pyrastri & Bombix rostrata \\
\hline Sericomyia (Sericomyia) lappona & $\begin{array}{l}\text { Anthophora quadrimaculata, Andrena flavipes, } \\
\text { Andrena labialis }\end{array}$ \\
\hline Sericomyia (Sericomyia) silentis & $\begin{array}{l}\text { Vespula vulgaris, Dolichovespula norvegica. } \\
\text { Dolichovespula sylvestris, Vespula austriaca, } \\
\text { Vespula germanica, Vespula rufa }\end{array}$ \\
\hline Sphegina (Sphegina) clunipes & Psenulus pallipes \\
\hline $\begin{array}{l}\text { Sphegina (Sphegina) elegans (Sphegina } \\
\text { kimakowiczi) }\end{array}$ & Psenulus pallipes \\
\hline Sphegina (Sphegina) verecunda & Psenulus pallipes \\
\hline Syrphus (Syrphus) ribesii (Sythus ribesii) & $\begin{array}{l}\text { Vespula vulgaris, Dolichovespula norvegica. } \\
\text { Dolichovespula sylvestris, Vespula austriaca, } \\
\text { Vespula germanica, Vespula rufa }\end{array}$ \\
\hline Syrphus (Syrphus) torvus (Sythus torvus) & $\begin{array}{l}\text { Vespula vulgaris, Dolichovespula norvegica. } \\
\text { Dolichovespula sylvestris, Vespula austriaca, } \\
\text { Vespula germanica, Vespula rufa }\end{array}$ \\
\hline $\begin{array}{l}\text { Syrphus (Syrphus) vitripennis (Sythus } \\
\text { vitripennis) }\end{array}$ & $\begin{array}{l}\text { Vespula vulgaris, Dolichovespula norvegica. } \\
\text { Dolichovespula sylvestris, Vespula austriaca, }\end{array}$ \\
\hline
\end{tabular}




\begin{tabular}{ll}
\hline & Vespula germanica, Vespula rufa \\
\hline Tropidia (Tropidia) scita & Nomada ruficornis, N. fabriciana \\
\hline Volucella bombylans haemorrhoidalis & Bombus pratorum \\
\hline Volucella bombylans var. bombylans & Bombus lapidarius \\
\hline Volucella bombylans var. plumata & Bombus terrestris, B. hortorum, B. jonellus, B. \\
& lucorum, B. magnus, B. soroeensis, Psithyrus \\
& barbutellus, $P$. bohemicus, P. vestalis \\
\hline Volucella inanis & Vespa crabro \\
\hline Volucella zonaria & Vespa crabro \\
\hline Xanthogramma festiva (Xanthogramma & Nomada goodeniana, N. fulvicornis \\
citrofasciatum) & \\
\hline Xanthogramma pedissequum & Crabro cribrarius \\
\hline
\end{tabular}

There was a significant relationship between mimics and their models for thorax and abdomen UV colour strength (thorax: $\mathrm{T}_{\mathrm{B}}(78)=0.224, \mathrm{p}=0.01$; abdomen: $\mathrm{T}_{\mathrm{B}}(78)=$ $0.419, \mathrm{p}<0.001$ ), but not for head or leg colour strength (head: $\mathrm{T}_{\mathrm{B}}(78)=0.156, \mathrm{p}=$ 0.064 ; legs: $\mathrm{T}_{\mathrm{B}}(78)=0.186, \mathrm{p}=0.057$; Figure 10). 

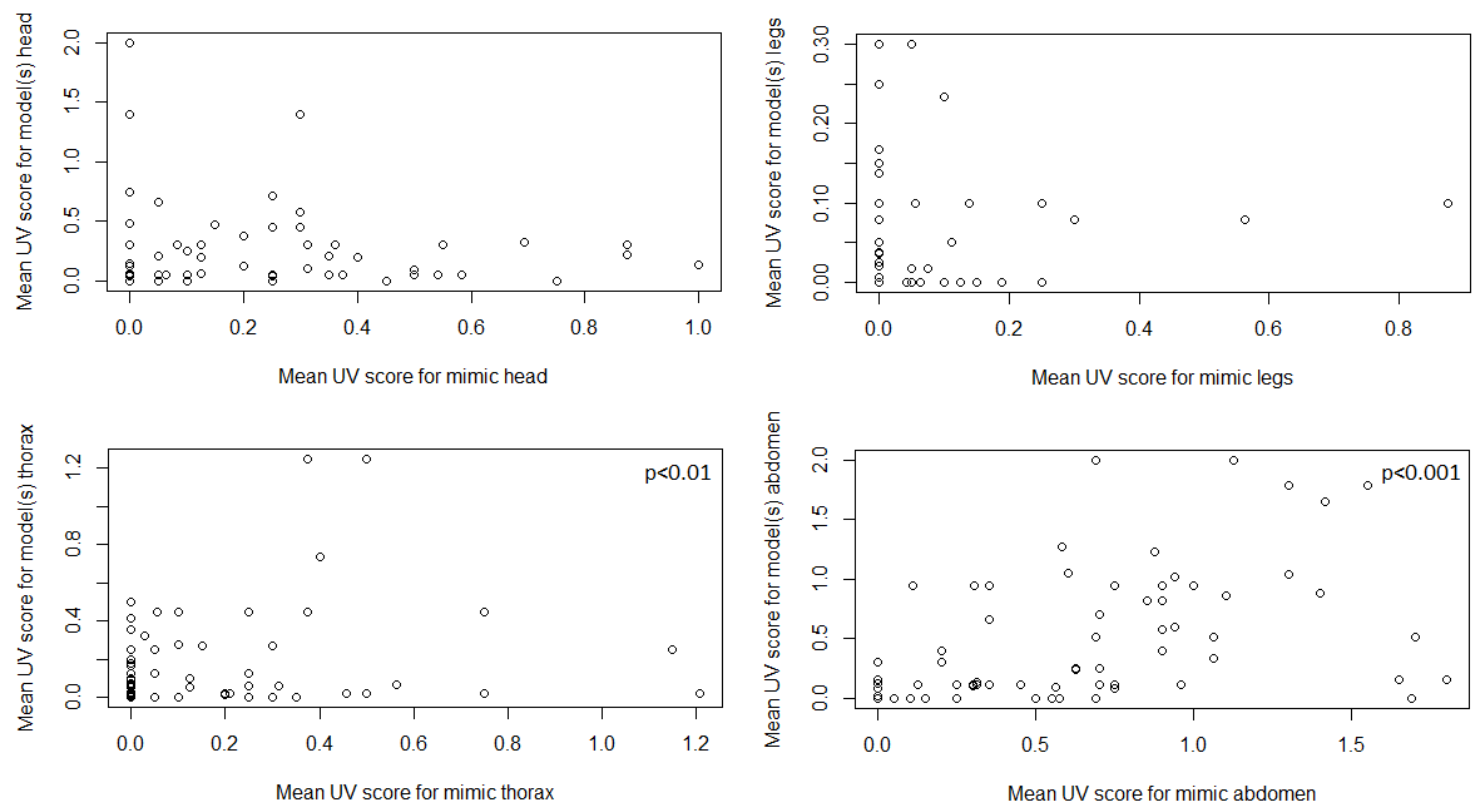

Figure 10. The mean UV colour strength score for of model(s) versus the mean UV colour strength score for the associated mimic for all four body regions. Results are marginally nonsignificant for head and legs, but significant for thorax and abdomen regions (head: $T_{B}(78)=0.156, p=0.064$; legs: $T_{B}(78)=0.186, p=0.057$; thorax: $T_{B}(78)=0.224, p=0.01 ;$ abdomen: $\left.T_{B}(78)=0.419, p<0.001\right)$.

Mimics were also significantly more similar (less different) to their own models than to non-models in terms of their UV colour strength $\left(\mathrm{t}_{79}=-3.492, \mathrm{p}<0.001\right.$; Figure 11). 


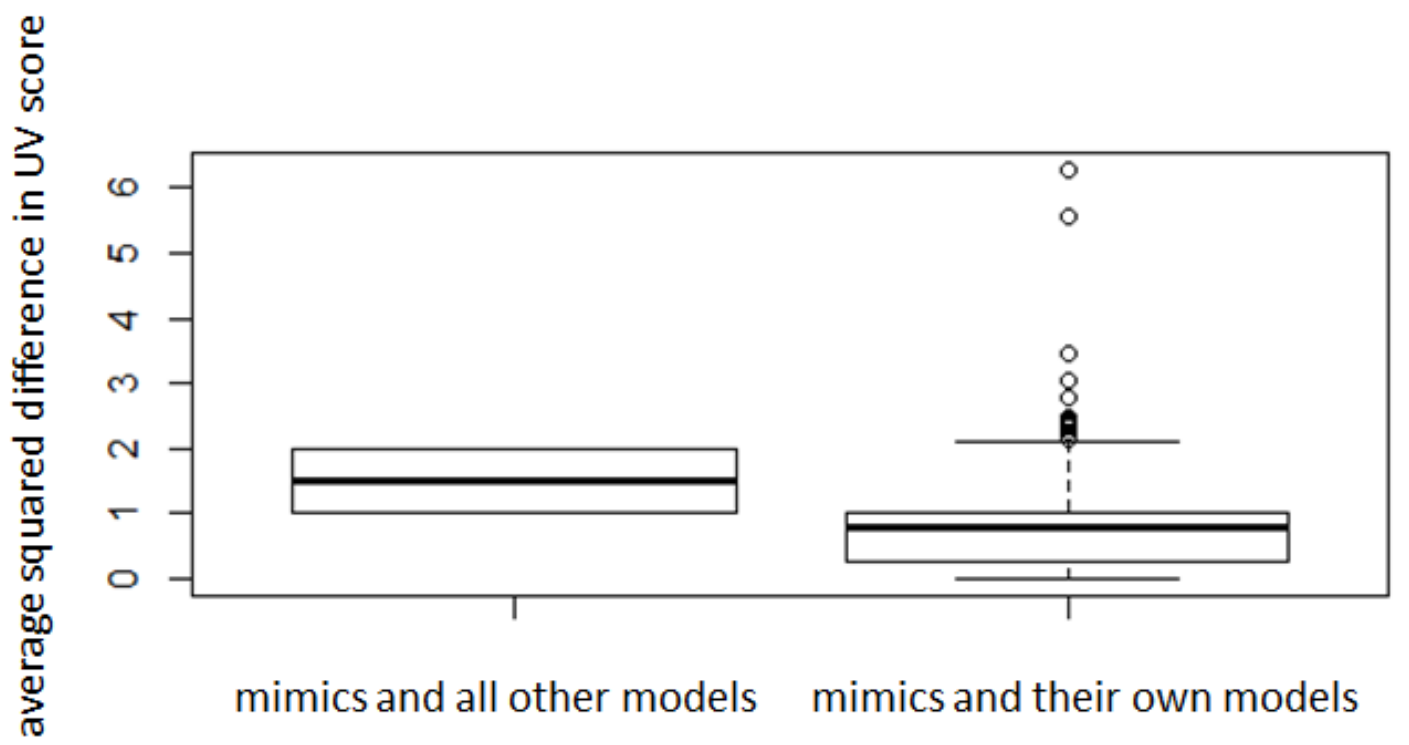

Figure 11. The average squared difference between the UV colour strength scores of a mimic and models. Each mimic species was compared to its own model(s) and to non-models. Results are significant $(\mathbf{t}(\mathbf{7 9})=-3.492, \mathbf{p}<0.001)$.

UV reflecting colour was more common in bees ( $88 \%$ of species) than in wasps $\left(25 \% ; \chi_{1}^{2}\right.$ $=24.7, \mathrm{p}<0.001)$. The reflecting colour was either found on the insect's cuticle or pile and the abdomen was the most common location for UV reflecting colour. The visible colours that reflected UV were white, yellow and pale orange (however visible colour cannot be used as a UV predictor since these colours did not always reflect UV; Figure 12). 


\section{A)}

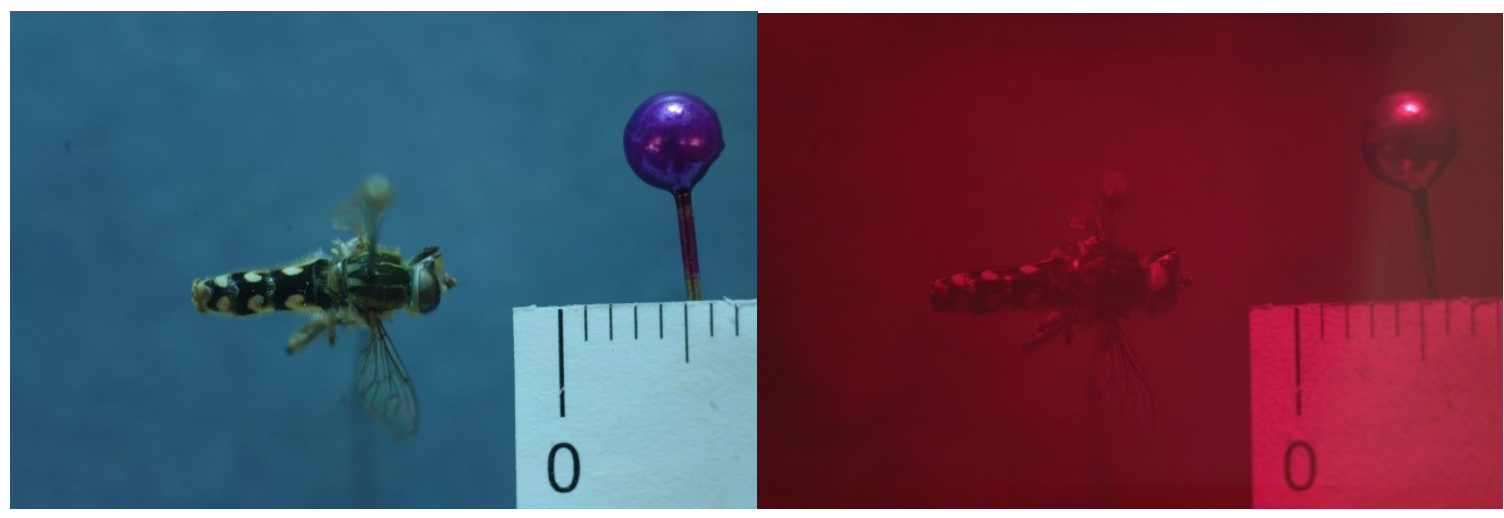

B)

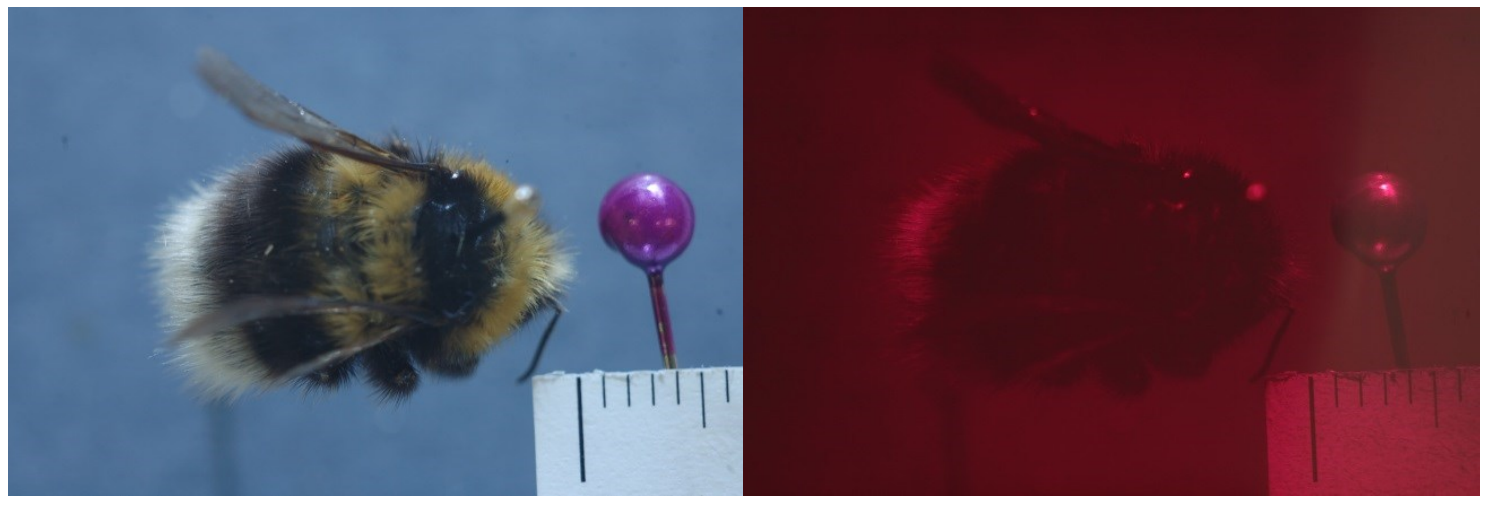

Figure 12. Two examples of the different types of UV colour. A) Cuticle colour (yellow in the human visible spectrum). B) Pile colour (white in the human visible spectrum).

\section{Microspectrophotometry}

All markings or body areas that were UV reflective in the photographs showed reflectance in the UV spectrum as measured by the microspectrophotometer (abdominal yellow) whereas areas without UV reflection in the photographs had much lower reflectance in the UV spectrum (abdominal black; Figure 13; Figure 14). The UV brightness values were best explained using model one, which included the human UV strength scores $\left(\chi^{2}{ }_{1}=199.126, \mathrm{p}<0.001\right)$. This means that the human UV strength scores correlate with the UV reflection (after controlling for human subject and specimen ID). 
A)

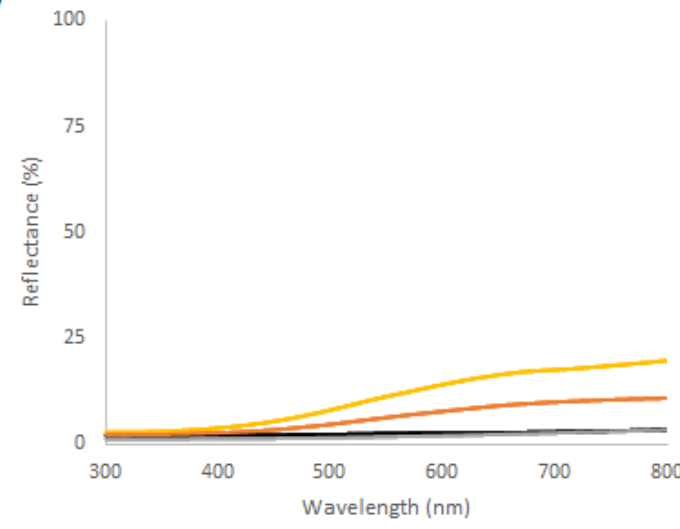

C)

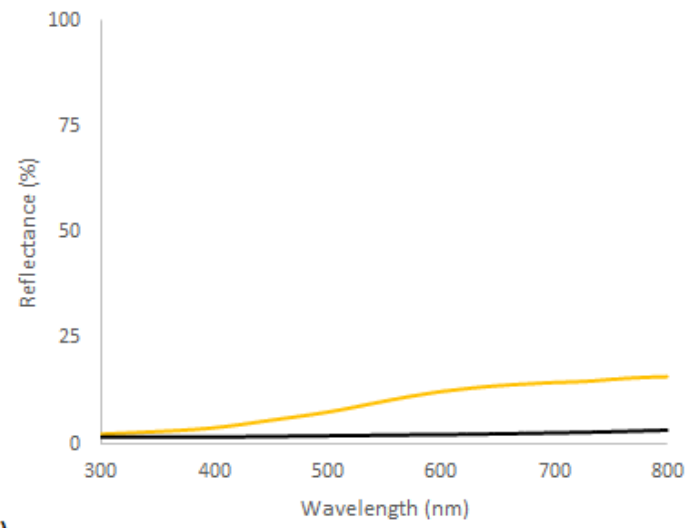

E)

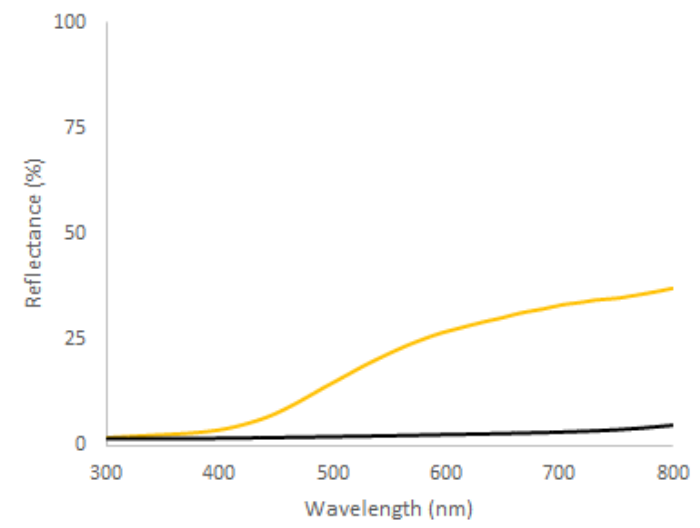

B)

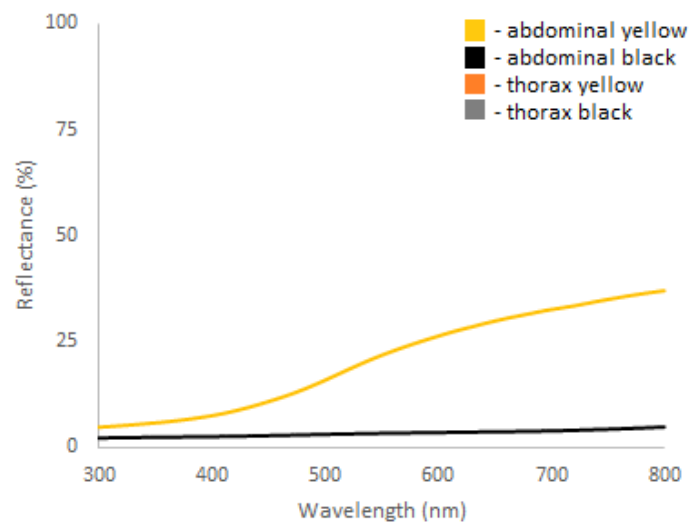

D)

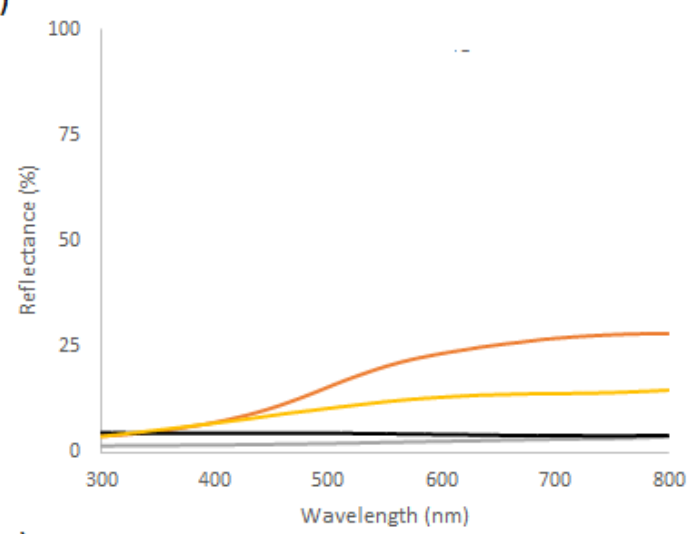

F)

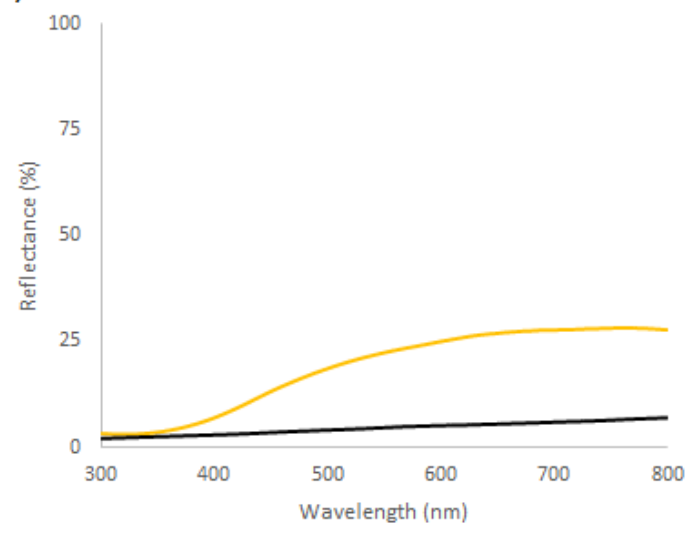

Figure 13. Averaged reflectance spectra for yellow thorax and abdominal colour and black thorax and abdominal colour for six species of hoverfly: A) Anasimyia lunulatus (1), B) Eristalis arbustorum (5), C) Eupeodes americanus or pomus (1), D) Eurimyia lineatus (1), E) Parasyrphus genualis (2), F) Platycheirus nearcticus (1). 

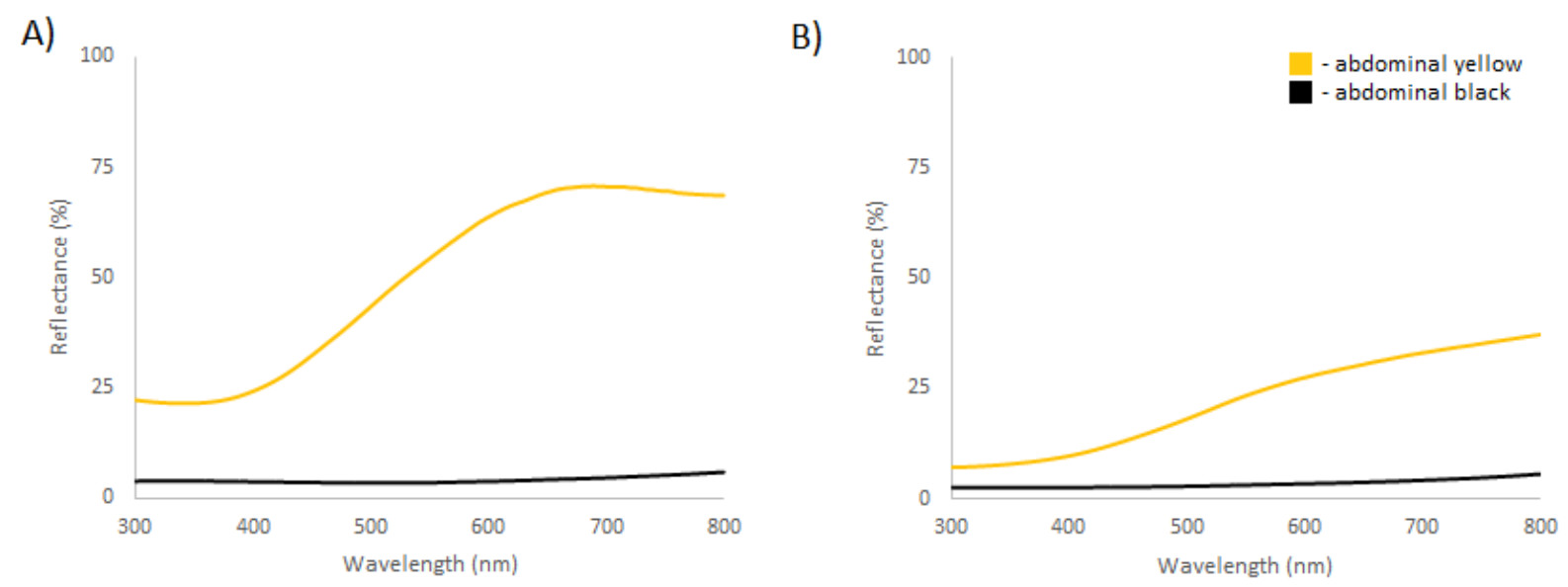

Figure 14. Averaged reflectance spectra for the yellow abdominal colour and the black abdominal colour of two species of hoverfly: A) Chalcosyrphus nemorum (2), B) Syritta pipiens (5).

\section{Discussion}

The majority of the species measured had fairly low reflectance in the UV spectrum (300 -400) with an increase in reflectance just before $400 \mathrm{~nm}$ (Figure 13). This increase in reflectance in the high 300 s is therefore what is causing the UV patterns in the UV photographs. Interestingly, despite the low reflectance in most species, S. pipiens showed a higher, and more even, reflectance from 300 to $400 \mathrm{~nm}$ (Figure 14). The UV reflection in these species is likely caused by gaps in the layer of yellow pigment which allow the reflective cuticle to be exposed and reflect UV wavelengths of light. C. nemorum had very high reflectance in the UV, as well as a strikingly different yellow spectral curve (Figure 14). It is possible that this species has a different mechanism for creating its yellow colour (because of its strikingly different reflectance curve) and it may have structural colour as opposed to pigments.

Although I was unfortunately unable to measure the actual spectra of the majority of the species examined, I did ensure that the human UV strength scores were meaningful indicators of the actual UV reflectance of a specimen, thereby validating this method.

UV reflecting colour was widespread in both the hoverfly and hymenopteran species examined. Although reflection in the UV spectrum is not special in any way, added 
reflection in the UV spectrum would increase the contrast of warning markings by increasing the brightness of the yellow or white body markings. Leaves and the majority of flowers are UV absorbing, and so by reflecting UV these insects would also increase their contrast against their natural backgrounds (Frohlich, 1976; Kevan et al., 1996). The relationship between mimic and model UV was non-significant for the head and leg body regions, but significant for the thorax and abdomen, with the strongest significance found for the abdomen. This makes sense because the majority of the patterns in these species are found on the abdomen, with some extending onto the thorax as well. Therefore there would be the strongest selection pressure on mimics to match their model's colours in these body regions, since predators would likely focus on them when learning which prey items were good to eat. The mimic and model groupings that I used for this study were created by humans using only the visible spectrum. The fact that the majority of these groupings hold up when analyzed solely using UV light (mimics are significantly more similar to their models than other non-models in UV) provides us with strong supportive evidence that the groupings are generally correct i.e. that models have not been frequently misassigned. It also provides further evidence that our UV scores are meaningful, in that such strong relationships in UV similarity are unlikely to arise by chance. The majority of the hoverflies measured by Taylor et al. (2016) did not have UV reflective colour however they primarily focused on wasp mimics and, as I discovered, UV reflective colour was more common in bees and therefore bee mimics.

However, it is important to note that there were several species of hoverfly that were in fact found to be more similar to all other models than to their own. The two most extreme outliers were Lejops vittatus and Anasimyia lineata. Interestingly, both these species were described as having only a single model: Coelioxys inermis. In this case the model species reflected UV more strongly than either of the mimics and so would appear a different colour to predators (Figure 15). 
A)

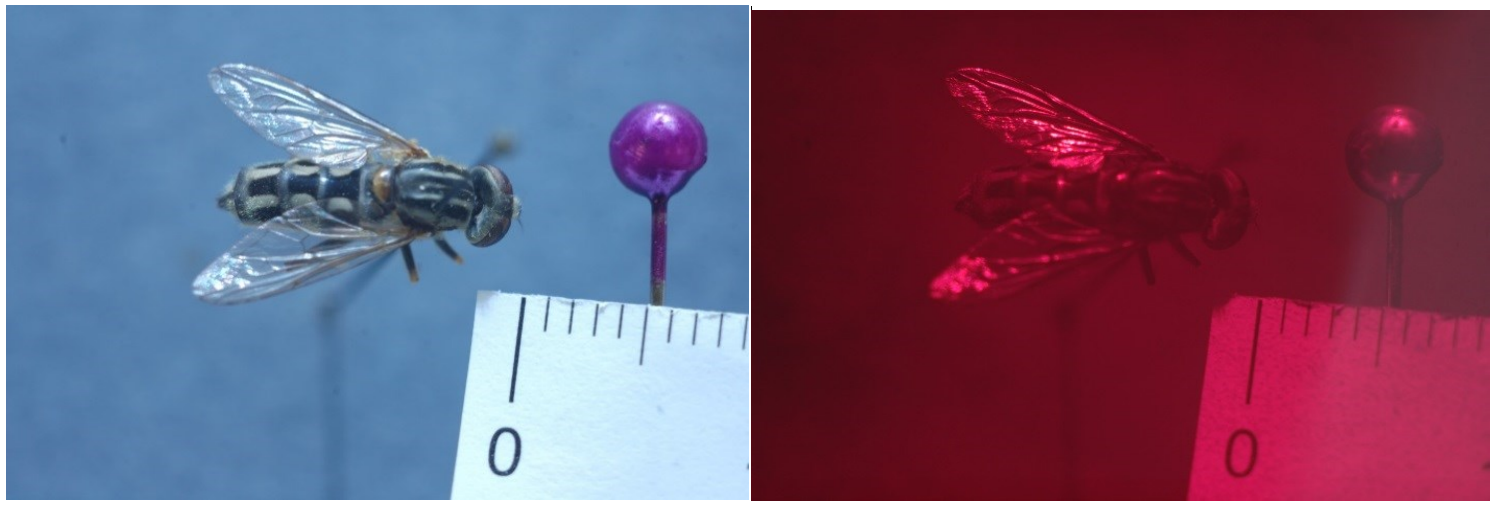

B)

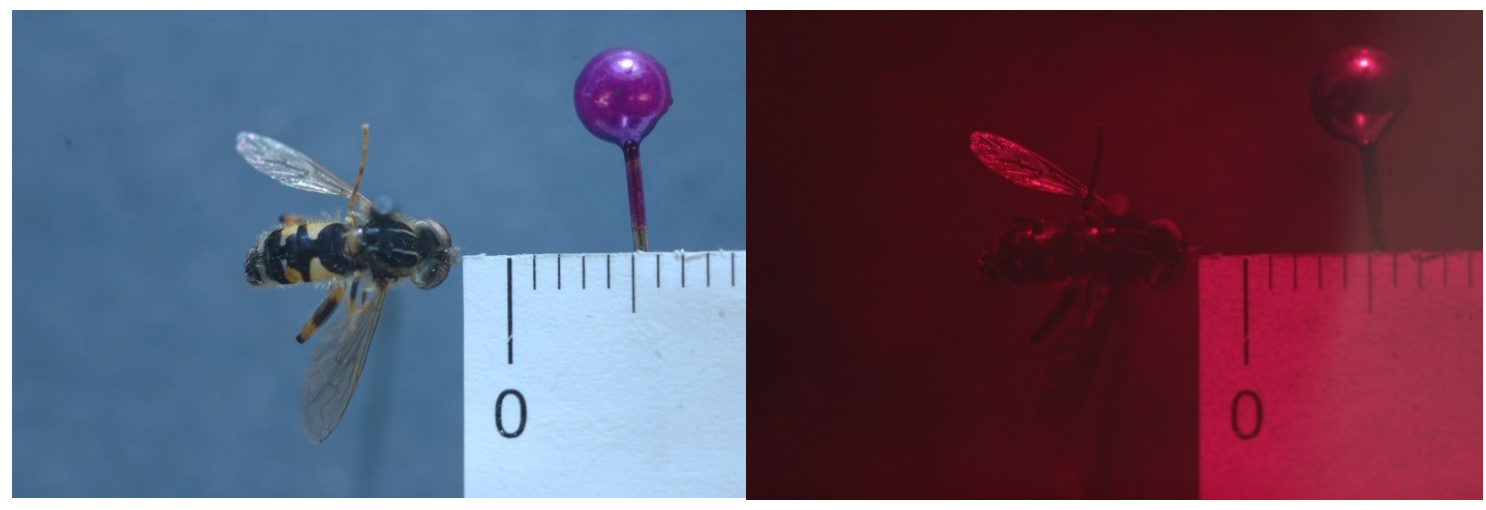

C)

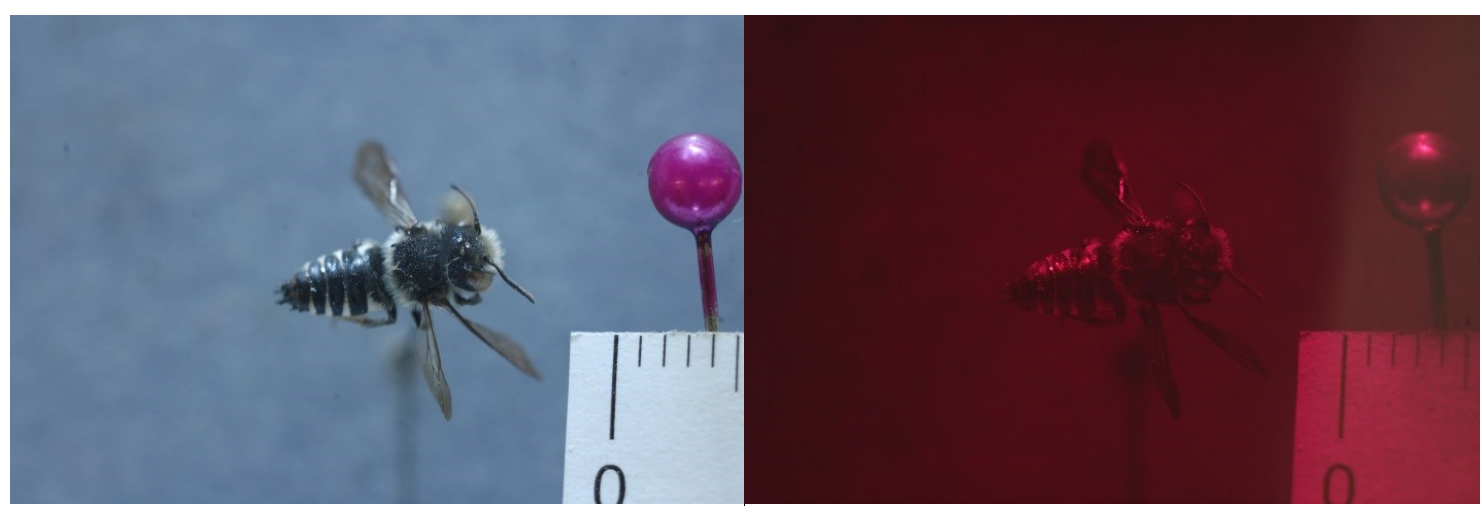

Figure 15. Visible and ultraviolet photos of A) Lejops vittatus, B) Anasimyia lineata and their bee model C) Coelioxys inermis. 
I believe that these mimics may have been assigned to the wrong model and could even be examples of "ugly ducklings" (imperfect mimics ("ducks") that are actually much more perfect ("swans") when matched with the correct model (Sherratt and Peet-Paré, under revision). Identifying poor mimic/model matches in the UV spectrum therefore has the potential to be a useful tool for assessing the validity of existing mimic/model groupings. The fact that there are no hard rules when it comes to predicting UV reflecting colour in hoverflies and hymenopterans means that UV photography or spectrophotometry must always be used to determine the presence of UV reflecting colour. The one exception to this seems to be white pile: all white pile was at least partially UV reflective and I therefore believe it is likely that all hymenopterans and hoverflies with white pile will be UV reflective, with abundant white pile resulting in a strong UV reflection. Although our findings primarily bolster the mimic and model groupings made using human vision they are also an important reminder that prey have evolved to fool their predators and that without considering a predator's perspective we have a narrowed and incomplete view. 


\section{References}

Armenta, J. K., Dunn, P. O., and Whittingham, L. A. (2008). Effects of specimen age on plumage color. Auk 125, 803-808.

Bennett, A. T. D., Cuthill, I. C., and Norris, K. J. (1994). Sexual selection and the mismeasure of color. Am. Nat. 144, 848-86.

Briscoe, A. D. and Chittka, L. (2001). The evolution of colour vision in insects. Annu. Rev. Entomol. 46, 471-510.

Brues, C. T. (1941). Photographic evidence on the visibility of color patterns in butterflies to the human and insect eye. P. Am. Acad. Arts Sci. 74, 281-286.

Burda, B. (2013). Unseen mimicry: how syrphid flies mimic UV colouration of their Models (Unpublished honour's thesis). Carleton University, Ottawa.

Burkhardt, D. (1982). Birds, berries and UV: A note on some consequences of UV vision in birds. Die. Natur. 69, 153-157.

Burkhardt, D. (1989). UV vision: a bird's eye view of feathers. J. Comp. Physiol. A 164, 787-796.

Burtt, E. H. (1981). The adaptiveness of animal colors. Bioscience 31, 723-729.

Byers, J. R. (1975). Tyndall blue and surface white of tent caterpillars, Malacosoma spp. J. Insect Physiol. 21, 401-415

Chapman, R. F. (1998). The insects: structure and function. Cambridge University Press.

Cherry M. I., and Bennett, A. T. (2001). Egg colour matching in an African cuckoo, as revealed by ultraviolet-visible reflectance spectrophotometry. P. Roy. Soc. BBiol. Sci. 268, 565-571.

Church, S. C., Bennett, A. T. D., Cuthill, I. C., Hunt, S., Hart, N. S., and Partridge, J. C. 
(1998). Does lepidopteran larval crypsis extend into the ultraviolet? Die. Natur. 85, 189-192.

Church, S. C., Cuthill, I. C., Bennett, A. T. D., and Partridge, J. C. (2004). Avian ultraviolet vision and its implications for insect defensive coloration. In H.V. Emden, and M. Rothschild (Eds.), Insect and Bird Interactions. (pp. 165 - 184). Andover UK: Intercept Press.

Coffin, D. (2015). DCRAW V. 9.26, https://www.cybercom.net/ dcoffin/dcraw/.

Cronin, T. W., Johnsen, S., Marshall, N. J., and Warrant, E. J. (2014). Visual Ecology, Princeton University Press.

Crothers, L. C. and Cummings, M. E. (2013). Warning signal brightness variation: sexual selection may work under the radar of natural selection in populations of a polytypic poison frog. Am. Nat. 181, E116-E124.

Cuthill, I. C. and Bennett, A. T. D. (1993). Mimicry and the eye of the beholder. P. Roy. Soc. B-Biol. Sci. 253, 203-204.

Defrize, J., Lazzari, C. R., Warrant, E. J., and Casas, J. (2011). Spectral sensitivity of a colour changing spider. J. Insect Physiol. 57, 508-513.

Dittrich, W., Gilbert, F., Green, P., McGregor, P., and Grewcock, D. (1993). Imperfect mimicry: a pigeon's perspective. Proc. R. Soc. B. 251, 195-200.

Doucet, S. M., and Hill. G. E. (2009). Do museum specimens accurately represent wild 
birds? A case study of carotenoid, melanin, and structural colours in long-tailed manakins Chiroxiphia linearis. J. Avian Biol. 40, 146-156.

Edmunds, M. (2008). Hoverflies: the garden mimic. Biologist 55, 202-207.

Edmunds, M. and Reader, T. (2014). Evidence for batesian mimicry in a polymorphic hoverfly. Evolution 68, 827-839.

Finger, E., and Burkhardt, D. (1994). Biological aspects of bird colouration and colour vision including ultraviolet range. Vision Res. 34, 1509-1514.

Fleishman, L. J., Loew, E. R., and Leal, M. (1993). Ultraviolet vision in lizards. Nature $365,397$.

Frohlich, M. W. (1976). Appearance of vegetation in ultraviolet light: absorbing flowers, reflecting backgrounds. Science 194, 839-841.

Garcia, C. M., and Burt de Perera, T. (2002). Ultraviolet-based female preferences in a viviparous fish. Behav. Ecol. Sociobiol. 52, 1-6.

Golding, Y., Ennos, R., Sullivan, M., and Edmunds, M. (2005). Hoverfly mimicry deceives humans. J. Zool. 266, 395-399.

Goldstein, G., Flory, K. R., Browne, B. A., Majid, S., Ichida, J. M., and Burtt, E. H. Jr. (2004). Bacterial degradation of black and white feathers. Auk 121, 656-659. 
Govardovskii, V. I. and Zueva, L. V. (1974). Spectral sensitivity of the frog eye in the ultraviolet and visible region. Vision Res. 14, 131-132.

Green, P. R., Gentle, L., Peake, T. M., Scudamore, R. E., McGregor, P. K., Gilbert, F., and Dittrich, W., H. (1999). Conditioning pigeons to discriminate naturally lit insect specimens. Behav. Process. 46, 97-102.

Gullan, P. J., and Cranston, P. S. (2010). The insects: An outline of entomology. West Sussex, UK: Wiley-Blackwell Publishing.

Hart, N. S. and Hunt, D. M. (2007). Avian visual pigments: Characteristics, spectral tuning, and evolution. Am. Nat. 169, S7-S26.

Harris, W. E., Forman, D. W., Battell, R. D., Battell, M. T. R., Nelson, A. K., and Brain, P. F. (2011). Odonata colour: More than meets the eye? Int. J. Odonatol. 14, 281289.

Hausmann, F., Arnold, K. E., Marshall, N. J., and Owens, I. P. F. (2003). Ultraviolet signals in birds are special. P. Roy. Soc. B-Biol. Sci. 270, 61-67.

Hinton, H. E. (1973). Some recent work on the colours of insects and their likely significance. Proc. Brit. Entomol. Natur. Hist. Soc. 6, 43-54.

Hinton, H. E. (1977). Subsocial behaviour and biology of some mexican Membracid bugs. Ecol. Entomol. 2, 61-79. 
Holloway, G., Gilbert, F., and Brandt, A. (2002). The relationship between mimetic imperfection and phenotypic variation in insect colour patterns. P. Roy. Soc. BBiol. Sci. 269, 411-416.

Howarth, B., and Edmunds, M. (2000). The phenology of Syrphidae (Diptera): Are they Batesian mimics of hymenoptera? Biol. J. Linn. Soc. 71, 437-457.

Howarth, B., Clee, C. and Edmunds, M. (2000). The mimicry between British Syrphidae (Diptera) and aculeate Hymenoptera. Brit. J. Ent. Nat. Hist. 13, 1-39.

Hunt, S., Bennett, A. T. D., Cuthill, I. C., and Griffiths, R. (1998). Blue tits are ultraviolet tits. P. Roy. Soc. B-Biol. Sci. 265, 451-455.

Hunt, D.M., Wilkie, S. E., Bowmaker, J.K., and Poopalasundaram, S. (2001). Vision in the ultraviolet. Cell. Mol. Life Sci. 58, 1583-1598.

Johnsen, S. (2012). The optics of life: A biologist's guide to light in nature, Princeton University Press.

Kelber, A., Vorobyev, M., and Osorio, D. (2003). Animal colour vision: behavioural tests and physiological concepts. Biol. Rev. 78, 81-118.

Kemp, D. J., Vukusic, P. and Rutowski, R. L. (2006). Stress-mediated covariance between nano-structural architecture and ultraviolet butterfly coloration. Funct. Ecol. 20, 282-289. 
Kevan, P., Giurfa, M., and Chittka, L. (1996). Why are there so many and so few white flowers? Trends Plant Sci. 1, 252-252.

Kikuchi, D. W. and Pfennig, D. W. (2013). Imperfect mimicry and the limits of natural selection. Q. Rev. Biol. 88, 297.

Lim, M.L.M., and Li, D. (2006). Extreme ultraviolet sexual dimorphism in jumping spiders (Araneae: Salticidae). Biol. J. Linn. Soc. 89, 397- 406.

Lim, M.L.M., and Li, D. (2007). Effects of age and feeding history on structure-based UV ornaments of a jumping spider (Araneae: Salticidae). Proc. Biol. Sci. $274,569-575$.

Loew, E. R. (1994). A third, ultraviolet-sensitive, visual pigment in the tokay gecko (gekko gekko).Vision Res. 34, 1427-1431.

Loew E. R. (2002). Visual pigments and oil droplets in diurnal lizards: a comparative study of Caribbean anoles. J. Exp. Biol. 205, 927-938

Losey, G. S., Cronin, T. W., Goldsmith, T. H., David, H., Marshall, N. J., and McFarland, W.N. (1999). The UV visual world of fishes: a review. J. Fish Biol. 54, 921-943.

Majerus, M. E. N., Brunton, C. F.A., and Stalker, J. (2000). A bird's eye view of the peppered moth. J. Evolution. Biol. 13, 155-159.

McNamara, M. E., Briggs, D. E. G., and Orr, P. J. (2012). The controls on the preservation of structural colour in fossil insects. Palaios 27, 443-454.

McNett, G. D., and Marchetti, K. (2005). Ultraviolet degradation in carotenoid patches: Live versus museum specimens of wood warblers (Parulidae). Auk 122, 793-802. 
Mitchell, F. L., and Lasswell, J. L. (2000). Digital dragonflies. Am. Entomol. 46, 110115.

Olofsson, M., Vallin, A., Jakobsson, S., and Wiklund, C. (2010). Marginal eyespots on butterfly wings deflect bird attacks under low light intensities with UV wavelengths. PloS One 5, e10798.

Osorio, D. and Vorobyev, M. (2008). A review of the evolution of animal colour vision and visual communication signals. Vision Res. 48, 2042-2051

Parker, A. R. (2000). 515 million years of structural colour. J. Opt. A-Pure Appl. Op. 2, R15-R28.

Pecháček, P., Stella, D., Keil, P., and Kleisner, K. (2014). Environmental effects on the shape variation of male ultraviolet patterns in the Brimstone butterfly (Gonepteryx rhamni, Pieridae, Lepidoptera). Die. Natur. 101, 1055-1063.

Penney, H. D., Hassall, C., Skevington, J. H., Abbott, K. R., and Sherratt, T. N. (2012). A comparative analysis of the evolution of imperfect mimicry. Nature $483,461-$ 466.

Penney, H. D., Hassall, C., Skevington, J. H., Lamborn, B., and Sherratt, T. N. (2014). The relationship between morphological and behavioral mimicry in hover flies (Diptera: Syrphidae). Am. Nat. 183, 281-289.

Pérez i de Lanuza, G., and Font, E. (2011). Lizard blues: blue body colouration and ultraviolet polychromatism in lacertids. Rev. Esp. Herp. 24, 67-84.

Pérez i de Lanuza, G. and Font, E. (2014). Ultraviolet vision in lacertid lizards: Evidence from retinal structure, eye transmittance, SWS1 visual pigment genes and behaviour. J. Exp. Biol. 217, 2899-2909. 
Pope, R. D. and Hinton, H. E. (1977). A preliminary survey of ultraviolet reflectance in beetles. Biol. J. Linn. Soc. 9, 331-348.

Robey, C. W. (1975). Observations on the breeding behavior of Pachydiplax longi-pennis Odonata: Libellulidae). Psyche 82, 89-96.

Ruxton, G. D., Sherratt, T. N., and Speed, M. P. (2004) Avoiding Attack: The Evolutionary Ecology of Crypsis, Warning Signals and Mimicry, Oxford University Press.

Schneider, C. A., Rasband, W. S., \& Eliceiri, K. W. (2012). NIH Image to ImageJ: 25 years of image analysis. Nat. methods 9, 671-675.

Shawkey, M. D., Pillai, S. R., Hill, G. E., Siefferman, L. M., and Roberts, S. R. (2007). Bacteria as an agent for change in structural plumage color: correlational and experimental evidence. Am. Nat. 169, S112 -S121.

Sherratt, T. N., and Peet-Paré, C. A. (under revision). The perfection of mimicry: an information approach. Philos. T. Roy. Soc. B-Biol. Sci.

Siebeck, U. E., Parker, A. N., Sprenger, D., Mäthger, L. M., and Wallis, G. (2010). A species of reef fish that uses ultraviolet patterns for covert face recognition. Curr. Biol. 20, 407-410.

Silberglied, R. E. (1973). Ultraviolet reflection of butterflies and its behavioral role in the genus Colias (Lepidoptera- Pieridae) (Doctoral dissertation). Harvard University. Silberglied, R. E. (1979). Communication in the ultraviolet. Annu. Rev. Ecol. Syst. 10, 373-398.

Silberglied, R. E., and Taylor, O. R. (1973). Ultraviolet differences between the Sulphur butterflies, Colias eurytheme and $C$. philodice, and a possible isolating 
mechanism. Nature (London) 241, 406-408.

Steinly, B. A., Deonier, D. L., and Regensburg, J. T. (1978). Scanning electron microscopy of ultraviolet-reflective pruinosity in species of Ochthera (Diptera: Ephydridae). Entomol. News 89, 117- 124.

Stelzer, R., Raine, N. E., Schmitt, K. D., and Chittka, L. (2010). Effects of aposematic coloration on predation risk in bumblebees? A comparison between differently coloured populations, with consideration of the ultraviolet. J. Zool. 282, 75-83.

Stevens, M, Párraga, C. A., Cuthill, I. C., Partridge, J. C., and Troscianko, T. S. (2007). Using digital photography to study animal coloration. Biol. J. Linn. Soc. 90, 211237.

Taylor, C. H., Reader, T., and Gilbert, F. (2016). Hoverflies are imperfect mimics of wasp colouration. Evol. Ecol. 30, 567-581.

Verhoeven, G.J., and Schmitt, K.D. (2010). An attempt to push back frontiers - digital near-ultraviolet aerial archaeology. J. Archaeol. Sci., 37 (4), 833-845.

Yamashita, S. and Tateda, H. (1976). Spectral sensitivities of jumping spider eyes. J. Comp. Physiol. 105, 29-41. 


\section{Appendices}

\section{Supplementary data for Table 3}

Exnerová, A., Ježová, D., Štys, P., Doktorovová, L., Rojas, B., and Mappes, J.

(2015). Different reactions to aposematic prey in 2 geographically distant populations of great tits. Behavioral Ecology, 26(5), 1361-1370. [UV, Birds, Lighting]

Leitão, A. V., Ferreira, A. C., Funghi, C., Trigo, S., \& Mota, P. G. (2015). Evidence for multiple functions in a sexually selected ornament. Animal Behaviour, 110, 155-161. [UV, Birds, Measured]

Fresnillo, B., Belliure, J., \& Cuervo, J. J. (2015). Red coloration in juvenile spiny-footed lizards, Acanthodactylus erythrurus, reduces adult aggression. Animal Behaviour, 102, 59-67. [UV, Reptiles/Amphibians, Measured]

Montoya, B., \& Torres, R. (2015). Male skin color signals direct and indirect benefits in a species with biparental care. Behavioral Ecology, 26(2), 425-434. [UV, Birds, Measured]

Yang, C., Wang, L., Cheng, S. J., Hsu, Y. C., Stokke, B. G., Røskaft, E., Moksnes, A., Liang, W., \& Møllere, A. P. (2015). Deficiency in egg rejection in a host species as a response to the absence of brood parasitism. Behavioral Ecology, 26(2), 406-415. [UV, Birds, Measured] 
Essenberg, C. J., Easter, R. A., Simmons, R. A., \& Papaj, D. R. (2015). The value of information in floral cues: bumblebee learning of floral size cues. Behavioral Ecology, 26(5), 1335-1344. [UV, Insects/arachnids, Models]

Clark, D. L., Macedonia, J. M., Rowe, J. W., Stuart, M. A., Kemp, D. J., \& Ord, T. J. (2015). Evolution of displays in Galapagos lava lizards: comparative analyses of signallers and robot playbacks to receivers. Animal Behaviour, 109, 33-44. [UV, Reptiles/amphibians, Models]

Muth, F., Keasar, T., \& Dornhaus, A. (2015). Trading off short-term costs for long-term gains: how do bumblebees decide to learn morphologically complex flowers? Animal Behaviour, 101, 191-199. [UV, Insects/arachnids, Models]

Pérez i de Lanuza, G., \& Font, E. (2015). Differences in conspicuousness between alternative color morphs in a polychromatic lizard. Behavioral Ecology, 26(5), 14321446. [UV, Reptiles/amphibians, Measured]

Avilés, J. M., Martín-Gálvez, D., De Neve, L., Soler, M., \& Soler, J. J. (2015). Ambient light in domed nests and discrimination of foreign egg colors. Behavioural Ecology and Sociobiology, 69, 425-435. [UV, Birds, Models] 
Crothers, L. R., \& Cummings, M. E. (2015). A multifunctional warning signal behaves as an agonistic status signal in a poison frog. Behavioral Ecology, 26(2), 560-568. [UV, Reptiles/amphibians, Measured, Models]

Martin, M., Meylan, S., Perret, S., \& Le Galliard, J. F. (2015). UV coloration influences spatial dominance but not agonistic behaviors in male wall lizards. Behavioural Ecology and Sociobiology, 69, 1483-1491. [UV, Reptiles/amphibians, Measured, Models]

Xu, M., \& Fincke, O. M. (2015). Ultraviolet wing signal affects territorial contest outcome in a sexually dimorphic damselfly. Animal Behaviour, 101, 67-74. [UV, Insects/arachnids, Measured, Models]

Zhou, M., Loew, E. R., \& Fuller, R. C. (2015). Sexually asymmetric colour-based species discrimination in orangethroat darters. Animal Behaviour, 106, 171-179. [UV, Fishes, Measured, Lighting]

Kniel, N., Dürler, C., Hecht, I., Heinbach, V., Zimmermann, L., \& Witte, K.. (2015). Novel mate preference through mate-choice copying in zebra finches: sexes differ. Behavioral Ecology, 26(2), 647-655. [UV, Birds, Lighting]

Diniz, P., Ramos, D. M., \& Macedo, R. H. (2015). Attractive males are less than adequate dads in a multimodal signalling passerine. Animal Behaviour, 102, 109117. [UV, Birds, Measured] 
Trigo, S., \& Mota, P. G. (2015). What is the value of a yellow patch? Assessing the signalling role of yellow colouration in the European serin. Behavioural Ecology and Sociobiology, 69, 481-490. [UV, Birds, Insects/arachnids, Measured, Lighting]

Zhang, S., Chen, H. L., Chen, K. Y., Huang, J. J., Chang, C. C., Piorkowski, D., Liao, C. P., \& Tso, I. M. (2015). A nocturnal cursorial predator attracts flying prey with a visual lure. Animal Behaviour, 102, 119-125. [UV, Insects/arachnids, Models]

Lin, T. S., Zhang, S., Liao, C. P., Hebets, E. A., \& Tso, I. M. (2015). A dual function of white coloration in a nocturnal spider Dolomedes raptor (Araneae: Pisauridae). Animal Behaviour, 108, 25-32. [UV, Insects/arachnids, Measured, Models]

Driessens, T., Huyghe, K., Vanhooydonck, B., \& Van Damme, R. (2015). Messages conveyed by assorted facets of the dewlap, in both sexes of Anolis sagrei. Behavioural Ecology Sociobiology, 69, 1251-1264. [UV, Reptiles/amphibians, Measured]

Abernathy, V. E., \& Peer, B. D. (2015). Mechanisms of egg recognition in brown-headed cowbird hosts: the role of ultraviolet reflectance. Animal Behaviour, 109, 73-79. [UV, Birds, Measured, Models]

Balenger, S. L., Bonneaud, C., Sefick, S., A., Edwards, S. V., \& Hill, G. E. (2015). 
Plumage color and pathogen-induced gene expression in a wild bird. Behavioral Ecology, 26(4), 1100-1110. [UV, Birds, Measured]

Bergman, M., Lessios, N., Seymoure, B. M., \& Rutowski, R. L. (2015). Mate detection in a territorial butterfly—-the effect of background and luminance contrast. Behavioral Ecology, 26(3), 851-860. [UV, Insects/arachnids, Models]

Desprat, J. L., Lengagne, T., Dumet, A., Desouhant, E., \& Mondy, N. (2015). Immunocompetence handicap hypothesis in tree frog: trade-off between sexual signals and immunity? Behavioral Ecology, 26(4), 1138-1146. [UV, Reptiles/amphibians, Measured]

Fabricant, S. A., \& Herberstein, M. E. (2015). Hidden in plain orange: aposematic coloration is cryptic to a colorblind insect predator. Behavioral Ecology, 26(1), 38-44. [UV, Insects/arachnids, Measured, Models]

Grunst, M. L., Grunst, A. S., Parker, C. E., Romero, L. M., \& Rotenberry, J. T. (2015). Pigment-specific relationships between feather corticosterone concentrations and sexual coloration. Behavioral Ecology, 26(3), 706-715. [UV, Birds, Measured]

Grunst, A. S., \& Grunst, M. L. (2015). Context-dependent relationships between multiple sexual pigments and paternal effort. Behavioral Ecology, 26(4), 1170-1179. [UV, Birds, Measured] 
Johnson, A. M., \& Fuller, R. C. (2015). The meaning of melanin, carotenoid, and pterin pigments in the bluefin killifish, Lucania goodei. Behavioral Ecology, 26(1), 158167. [UV, Fishes, Measured, Lighting]

Kang, C., Stevens, M., Moon, J. Y., Lee, S. I., \& Jablonski, P. G. (2015). Camouflage through behavior in moths: the role of background matching and disruptive coloration. Behavioral Ecology, 26(1), 45-54. [UV, Insects/arachnids, Measured]

O’Hanlon, J. C., Herberstein, M. E., \& Holwell, G. I. (2015). Habitat selection in a deceptive predator: maximizing resource availability and signal efficacy. Behavioral Ecology, 26(1), 194-199. [UV, Insects/arachnids, Models]

Wolf, S., Roper, M., \& Chittka, L. (2015). Bumblebees utilize floral cues differently on vertically and horizontally arranged flowers. Behavioral Ecology, 26(3), 773-781. [UV, Insects/arachnids, Models]

Yong, L., Woodall, B. E., Pierotti, M. E. R., \& McKinnon, J. S. (2015). Intrasexual competition and throat color evolution in female three-spined sticklebacks. Behavioral Ecology, 26(4), 1030-1038. [UV, Fishes, Measured, Lighting] 
Andersson, M. (2015). Aposematism and crypsis in a rodent: antipredator defence of the Norwegian lemming. Behavioural Ecology and Sociobiology, 69, 571-581. [No UV, Birds, Measured]

Wheatcroft, D. (2015). Repetition rate of calls used in multiple contexts communicates presence of predators to nestlings and adult birds. Animal Behaviour, 103, 35-44. [No UV, Birds, Models]

Santana, A. F. K., McClure, M., Ethier, J., \& Despland, E. (2015). Exploration costs promote conservative collective foraging in the social caterpillar Malacosoma disstria. Animal Behaviour, 105, 245-250. [No UV, Insects/arachnids, Lighting]

Theis, A., Bosia, T., Roth, T., Salzburger, W., \& Egger, B. (2015). Egg-spot pattern and body size asymmetries influence male aggression in haplochromine cichlid fishes. Behavioral Ecology, 26(6), 1512-1519. [No UV, Fish, Lighting]

Stoffer, B., \& Uetz, G. W. (2015). The effects of social experience with varying male availability on female mate preferences in a wolf spider. Behavioural Ecology and Sociobiology, 69, 927-937. [No UV, Insects/arachnids, Models]

Lyon, B. E., Shizuka, D., \& Eadie, J. M. (2015). Interspecific egg rejection as ecological collateral damage from selection driven by conspecific brood parasitism. Animal Behaviour, 103, 117-124. [No UV, Birds, Models] 
Yang, C., Hu, Y., Ma, M., Liang, W., \& Møller, A. P. (2015). Absence of egg rejection in an Asian population of house sparrow (Passer domesticus), a conspecific brood parasite in Europe. Behavioural Ecology and Sociobiology, 69, 723-727. [No UV, Birds, Models]

Schweitzer, C., Motreuil, S., \& Dechaume-Moncharmont, F. X. (2015). Coloration reflects behavioural types in the convict cichlid, Amatitlania siquia. Animal Behaviour, 105, 201-209. [No UV, Fishes, Measured]

Tedore, C., \& Johnsen, S. (2015). Visual mutual assessment of size in male Lyssomanes viridis jumping spider contests. Behavioral Ecology, 26(2), 510-518. [No UV, Insects/arachnids, Models]

Bierbach, D., Sommer-Trembo, C., Hanisch, J., Wolf, M., \& Plath, M. (2015). Personality affects mate choice: bolder males show stronger audience effects under high competition. Behavioral Ecology, 26(5), 1314-1325. [No UV, Fishes, Lighting]

Auld, H. L., Jeswiet, S. B., \& Godin, J. G. J. (2015). Do male Trinidadian guppies adjust their alternative mating tactics in the presence of a rival male audience? Behavioural Ecology and Sociobiology, 69, 1191-1199. [No UV, Fish, Measured] 
Auld, H. L., \& Godin, J. G. J. (2015). Sexual voyeurs and copiers: social copying and the audience effect on male mate choice in the guppy. Behavioural Ecology and Sociobiology, 69, 1795-1807. [No UV, Fish, Measured]

Brommer, J. E., Karell, P., Aaltonen, E., Ahola, K., \& Karstinen, T. (2015). Dissecting direct and indirect parental effects on reproduction in a wild bird of prey: dad affects when but not how much. Behavioural Ecology and Sociobiology, 69, 293-302. [No UV, Birds, Measured]

Heinen-Kay, J. L., Morris, K. E., Ryan, N. A., Byerley, S. L., Venezia, R. E.,Peterson, M. N., \& Langerhans, R. B. (2015). A trade-off between natural and sexual selection underlies diversification of a sexual signal. Behavioral Ecology, 26(2), 533-542. [No UV, Fishes, Models]

Borner, K. K., Krause, S., Mehner, T., Uusi-Heikkilä, S., Ramnarine, I. W., \& Krause, J. (2015). Turbidity affects social dynamics in Trinidadian guppies. Behavioural Ecology and Sociobiology, 69, 645-651. [No UV, Fishes, Models]

Wang, L., Yang, C., Møller, A. P., Liang, W., \& Lu, X. (2015). Multiple mechanisms of egg recognition in a cuckoo host. Behavioural Ecology and Sociobiology, 69, 1761-1767. [No UV, Birds, Lighting] 
Herdegen, M., \& Radwan, J. (2015). Effect of induced mutations on sexually selected traits in the guppy, Poecilia reticulata. Animal Behaviour, 110, 105 -111. [No UV, Fishes, Measured]

Rosenthal, M. F., \& Hebets, E. A. (2015). Temporal patterns of nutrition dependence in secondary sexual traits and their varying impacts on male mating success. Animal Behaviour, 103, 75-82. [No UV, Insects/arachnids, Measured]

Barquero, M. D., Peters, R., \& Whiting, M. J. (2015). Geographic variation in aggressive signalling behaviour of the Jacky dragon. Behavioural Ecology and Sociobiology, 69, 1501-1510. [No UV, Reptiles/amphibians, Lighting]

Hasegawa, M., Giraudeau, M., Kutsukake, N., Watanabe, M., \& McGraw, K. J. (2015).Bayesian estimation of competitiveness in male house finches: small-billed males are more competitive. Animal Behaviour, 108, 207-214. [No UV, Birds, Measured]

Wund, M. A., Baker, J. A., Golub, J. L., \& Foster, S. A. (2015). The evolution of antipredator behaviour following relaxed and reversed selection in Alaskan threespine stickleback fish. Animal Behaviour, 106, 181-189. [No UV, Fishes, Models, Lighting]

Nafus, M. G., Germano, J. M., Perry, J. A., Todd, B. D., Walsh, A., \& Swaisgood, R. R. (2015). Hiding in plain sight: a study on camouflage and habitat selection in a slow- 
moving desert herbivore. Behavioral Ecology, 26(5), 1389-1394. [No UV, Birds, Reptiles/amphibians, Measured]

Plasman, M., Reynoso, V. H., Nicolás, L., \& Torres, R. (2015). Multiple colour traits signal performance and immune response in the Dickerson's collared lizard Crotaphytus dickersonae. Behavioural Ecology and Sociobiology, 69, 765-775. [No UV, Reptiles/amphibians, Measured]

Greaney, N. E., Mannion, K. L., \& Dzieweczynski, T. L. (2015). Signaling on Prozac: altered audience effects on male-male interactions after fluoxetine exposure in Siamese fighting fish. Behavioural Ecology and Sociobiology, 69, 1925-1932. [No UV, Fishes, Measured]

Tinghitella, R. M., Lehto, W. R., \& Minter, R. (2015). The evolutionary loss of a badge of status alters male competition in three-spine Stickleback. Behavioral Ecology, 26(2), 609-616. [No UV, Fishes, Measured]

Leclaire, S., Bourret, V., 4 \& Blanchard, P., de Franceschi, C., Merkling, T., Hatch, S. A., \& Danchin, E. (2015). Carotenoids increase immunity and sex specifically affect color and redox homeostasis in a monochromatic seabird. Behavioural Ecology and Sociobiology, 69, 1097-1111. [No UV, Birds, Measured] 
Suzuki, T. N., \& Sakurai, R. (2015). Bent posture improves the protective value of bird dropping masquerading by caterpillars. Animal Behaviour, 105, 79-84. [No UV, Birds, Insects/arachnids, Models]

Odreitz, U., \& Sefc, K. M. (2015). Territorial competition and the evolutionary loss of sexual size dimorphism. Behavioural Ecology and Sociobiology, 69, 593-601. [No UV, Fishes, Lighting]

Devigili, A., Doldán-Martelli, V., \& Pilastro, A. (2015). Exploring simultaneous allocation to mating effort, sperm production, and body growth in male guppies. Behavioral Ecology, 26(4), 1203-1211. [No UV, Fishes, Measured, Lighting]

Gangoso, L., Afán, I., Grande, J. M., \& Figuerola, J. (2015). Sociospatial structuration of alternative breeding strategies in a color polymorphic raptor. Behavioral Ecology, 26(4), 1119-1130. [No UV, Birds, Models]

Ninnes, C. E., Adrion, M., Edelaar, P., Tella, J. L., \& Andersson, S. (2015). A receiver bias for red predates the convergent evolution of red color in widowbirds and bishops. Behavioral Ecology, 26(4), 1212-1218. [No UV, Birds, Models] 